\begin{abstract}
Title of the Document:

DESIGN AND DEVELOPMENT OF POTASSIUM FORMATE BASED ATMOSPHERIC WATER HARVESTER
\end{abstract}

Veeresh Ayyagari, M.S., 2019

Directed By:

Professor Jungho Kim, Department of Mechanical Engineering

With the deteriorating climate and rapid depletion of natural resources, the problem of water scarcity is on the rise and there is a pressing need for sustainable technologies to address this problem. The extraction of water from air has been identified as a potential solution to address the water scarcity problem in arid regions that do not have ready access to seawater. Much of the research in the literature in tackling this problem has been focused on the use of heat pumps and the use of Atmospheric Water Harvesters (AWH) via solid desiccant technologies. Very little work has been done on utilizing the potential of liquid desiccants for the extraction of water using potassium formate. Through this thesis, we have designed and developed a novel and low-cost AWH utilizing (i) an aqueous solution of potassium formate as the medium for absorption of moisture during the night when the relative humidity is high and (ii) solar energy for removal of absorbed moisture from the desiccant solution during the day. A prototype was built and a performance of 1.9 $\mathrm{kg} / \mathrm{m}^{2} /$ day with a moisture uptake of $0.34 \mathrm{~kg}$ of water $/ \mathrm{kg}$ of salt was recorded. 


\section{DESIGN AND DEVELOPMENT OF POTASSIUM FORMATE BASED ATMOSPHERIC WATER HARVESTER}

by

Veeresh Ayyagari

Thesis submitted to the Faculty of the Graduate School of the University of Maryland, College Park, in partial fulfillment of the requirements for the degree of

\section{Master of Science}

2019

Advisory Committee:

Professor Jungho Kim, Chair

Professor Gary Pertmer

Research Professor Yunho Hwang 
(C) Copyright by

Veeresh Ayyagari

2019 


\section{Acknowledgments}

I would like to thank my advisor Dr. Jungho Kim and co-advisor Dr. Yunho Hwang for providing an opportunity to work on this project and for their encouragement and patience in discussing different ideas and guidance from the start of the project to the completion of my thesis. I appreciate the financial support provided by the Clark Foundation for the completion of the project.

I would like to thank members from Phase Change and Heat Transfer Lab, Dr. Ratnesh Tiwari for his help in providing inputs that have helped in improving the pace of the project and other lab members for their constant support over two years in completing the project.

I would like to thank my parents and friends who were constant support of motivation and am grateful to have them in my life. 


\section{Table of Contents}

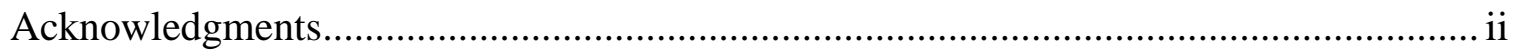

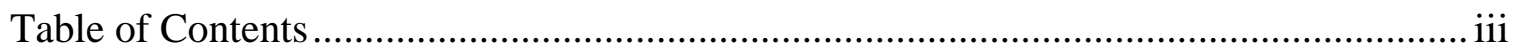

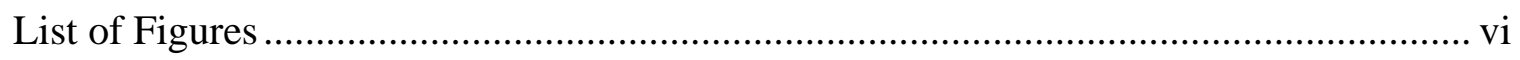

List of tables.................................................................................................. vii

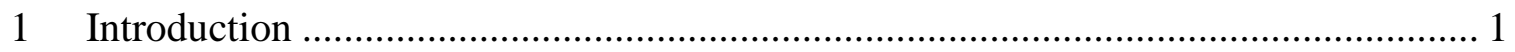

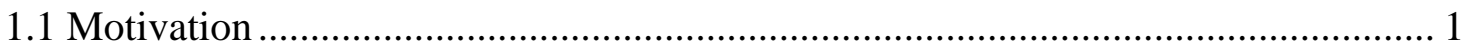

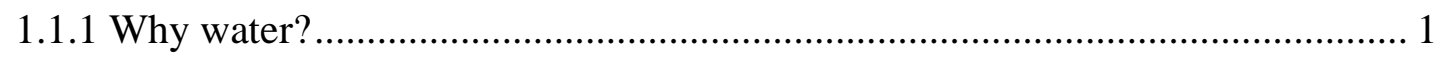

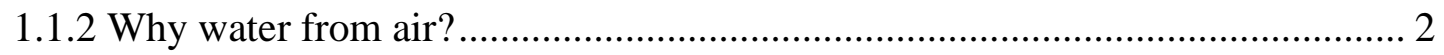

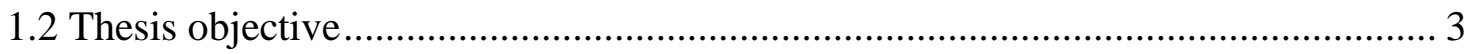

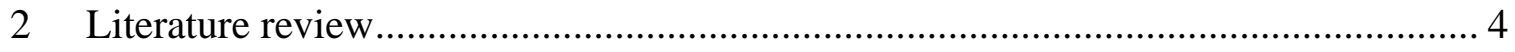

2.1 Current AWH techniques .................................................................... 5

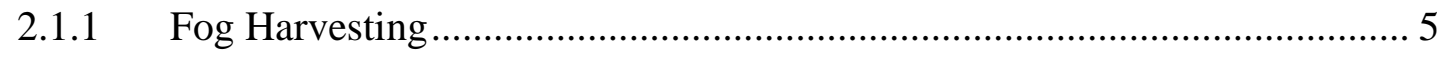

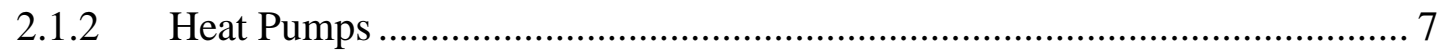

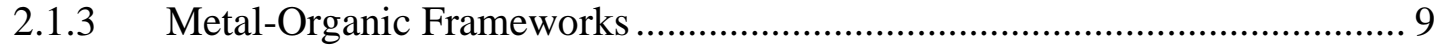

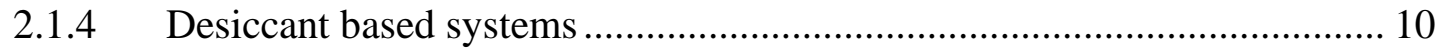

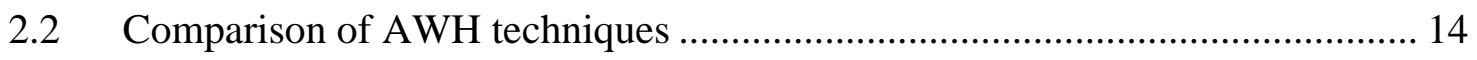

2.2.1 Heat pump versus desiccant based systems ....................................... 14

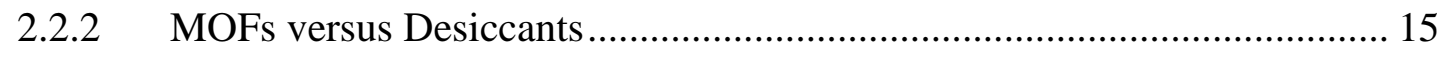


2.2.3 Comparison of solid and liquid desiccant systems ............................... 16

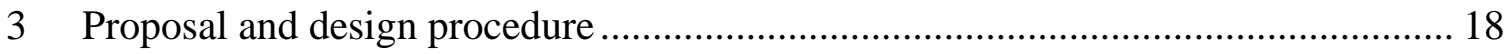

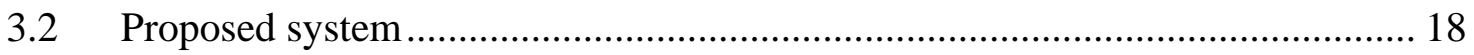

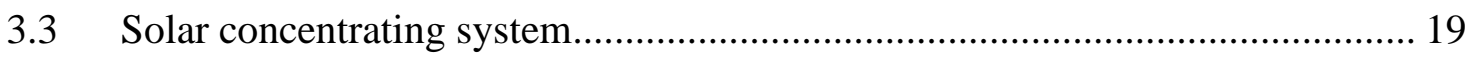

3.3.1 Compound parabolic concentrators ............................................... 20

3.3.2 Evacuated tube collectors ............................................................. 21

3.3.3 Mechanism of heat transfer in combined CPC and ETC ......................... 22

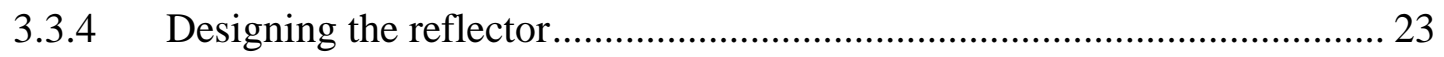

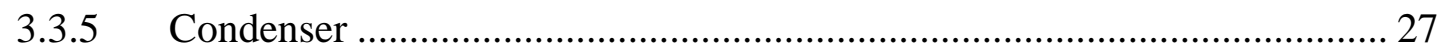

3.3.6 Performance metrics of solar concentrating system …........................... 27

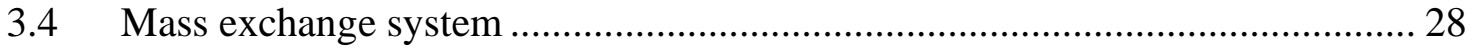

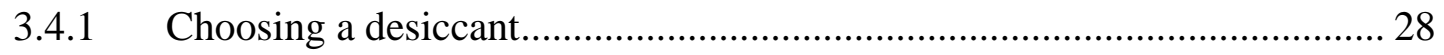

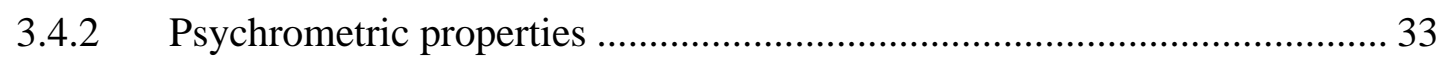

3.4.3 Designing a mass exchange system .................................................. 34

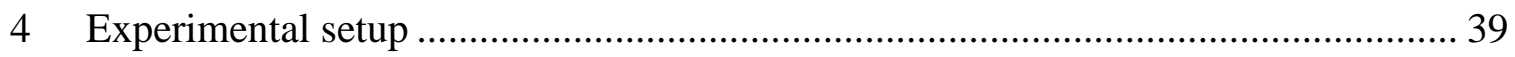

4.2 Schematic and operation of the proposed system ...................................... 39

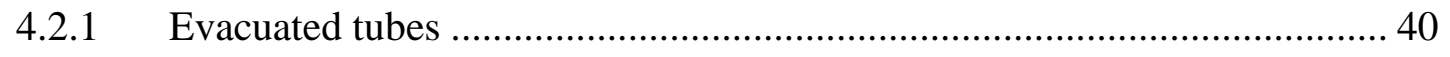

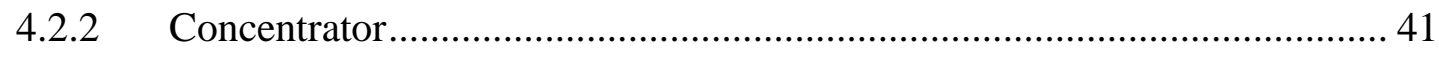

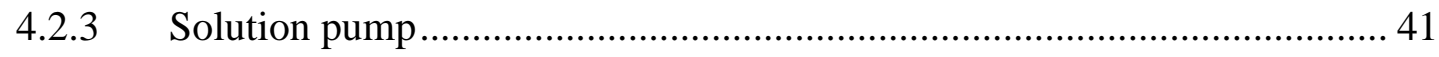

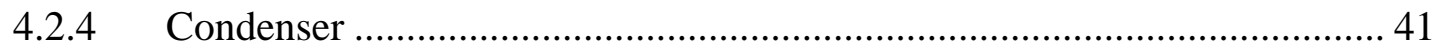




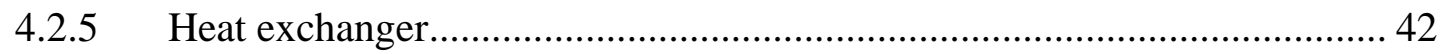

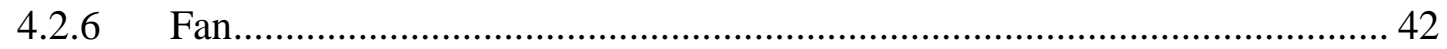

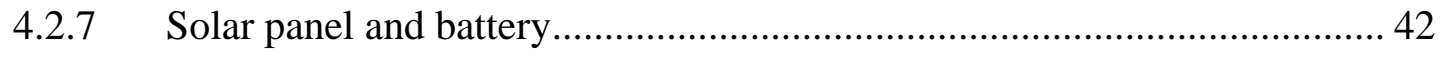

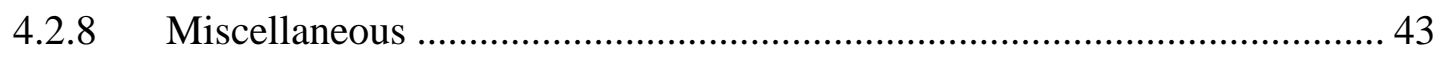

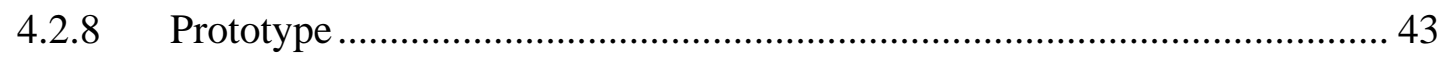

4.3 Measurements and uncertainties .......................................................... 44

4.3.1 Measuring Relative Humidity and Temperature.................................... 44

4.3.2 Measuring density and temperature of liquid desiccant .............................. 45

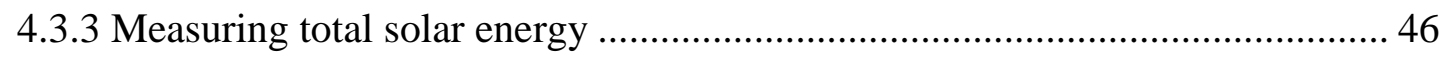

4.3.4 Measuring the total moisture absorbed.................................................. 47

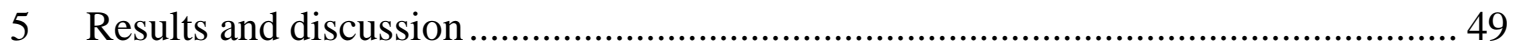

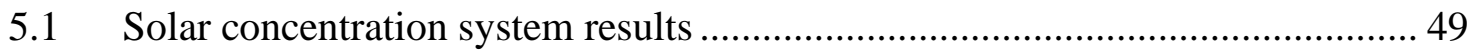

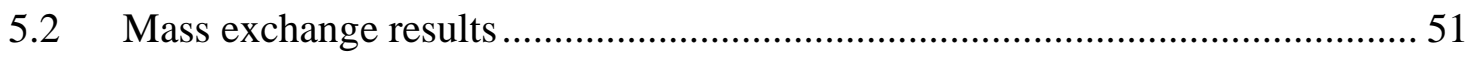

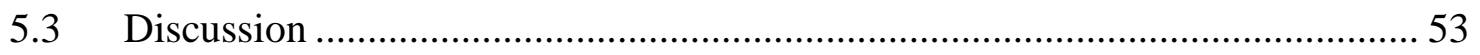

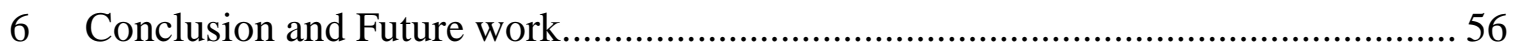

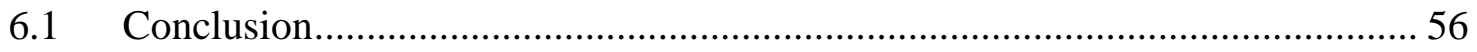

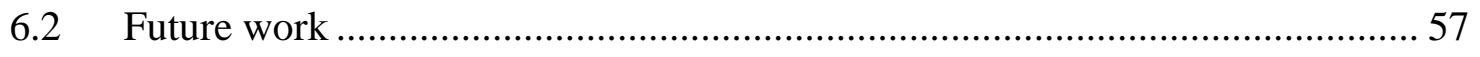

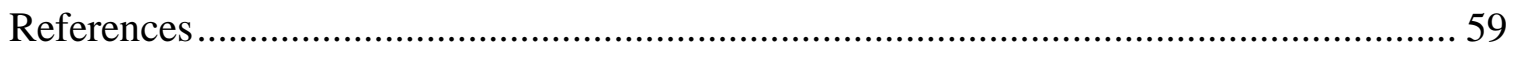




\section{List of Figures}

Figure 1 Fog collectors installed in a mountainous region in Chile [18]........................ 6

Figure 2 Heat pump generating freshwater from the air [19] ................................... 7

Figure 3 Thermoelectric solar still designed and fabricated by Rahbar and Esfahani [24] 8

Figure 4 water extraction device utilizing MOFs [26].......................................... 9

Figure 5 Solar still schematic proposed by Abualhamayel and Gandhidasan [34] ......... 12

Figure 6 A) Solar still developed by Gandhidasan [37] and B) Trapezoidal shelve system

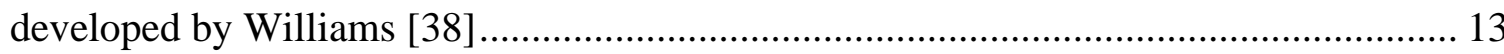

Figure 7 Water absorption isotherms for MOF-801, MOF-841, UiO-66, PIZOF-2 at $25^{\circ} \mathrm{C}$

[27]. 15

Figure 8 Water absorption isotherms for liquid desiccants, ................................... 16

Figure 9 Proposed moisture desorption process .................................................... 18

Figure 10 Proposed moisture absorption process .................................................. 19

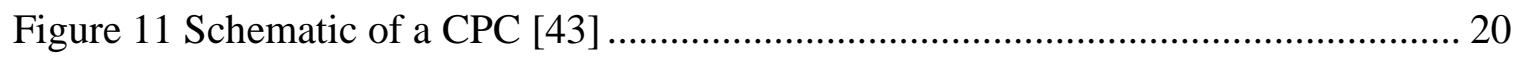

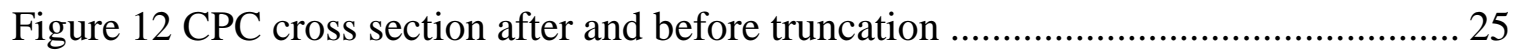

Figure 13 Vapor pressure graphs for potassium formate at various mass concentrations

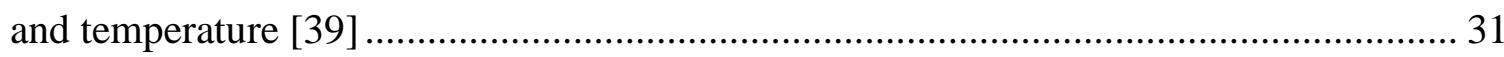

Figure 14 Variation of TCT with the density of potassium formate [46] ....................... 32

Figure $15 \mathrm{RH}$ equilibrium chart for potassium formate at various concentrations [39] ... 33

Figure 16 Types of dehumidifiers A) Adiabatic dehumidifier B) Internally cooled

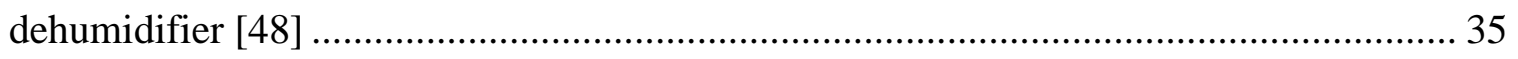


Figure 17 Various flow configurations in a dehumidifier A) Parallel flow dehumidifier B)

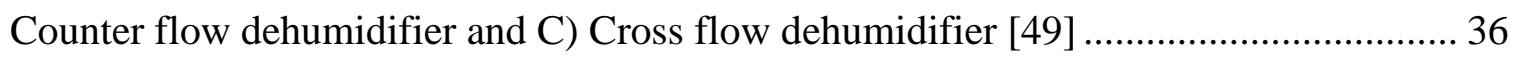

Figure 18 A) Ceramic raschig rings and B) Polypropylene palls used in random packing

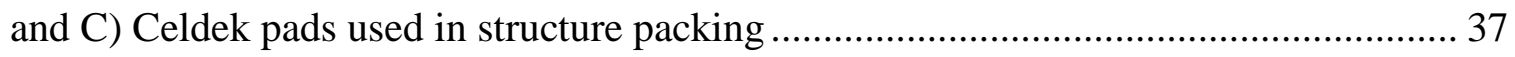

Figure 19 Schematic of the proposed liquid desiccant based AWH............................. 39

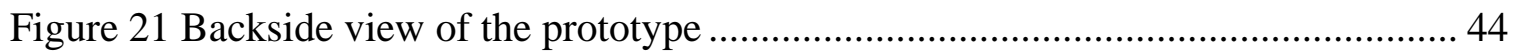

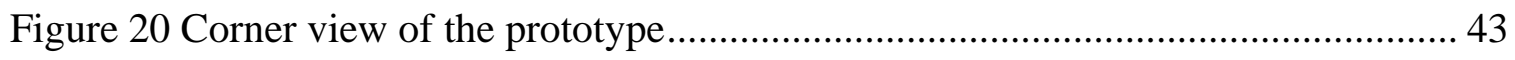

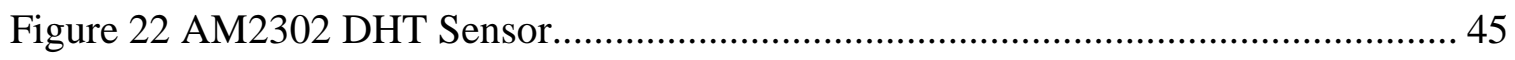

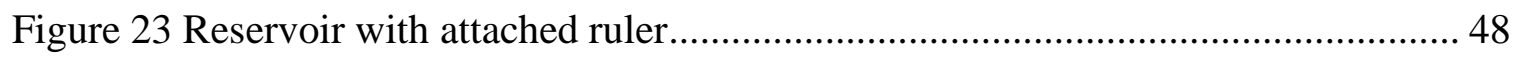

Figure 24 Estimated solar radiation variation with time for October 10 th ..................... 50

Figure 25 Trend of RH and temperature of process air at inlet and exit of dehumidifier 52 


\section{List of tables}

Table 1 Summary of the comparison of existing water extraction methods.................... 17

Table 2 Geometrical and optical parameters of CPC .............................................. 26

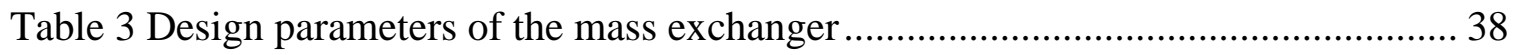

Table 4 Technical details of the humidity sensor .................................................... 45

Table 5 Technical parameters of a mass flow meter as given by the manufacturer ........ 46

Table 6 Technical parameters of digital light meter as given by the manufacturer......... 47

Table 7 Results for trials performed on solar concentration system............................ 49

Table8 Results for solar concentration system trials performed on October 10th........... 51

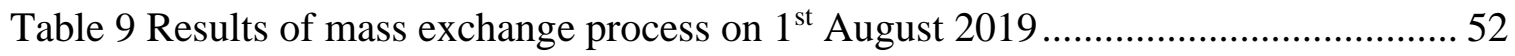




\section{Introduction}

\subsection{Motivation}

\subsubsection{Why water?}

Water is elemental and is vital for the survival of almost any kind of organism on the planet. $71 \%$ of the earth's surface is covered with water and mostly in seas and oceans. Freshwater is essential for the survival of humankind. Though there is an ample amount of water available on the earth, most of the water is not fresh and is not readily available for human consumption. Only $3 \%$ of the world's water is freshwater, and two-thirds of that is tucked away in frozen glaciers or otherwise in unavailable form [1].

Water scarcity is the lack of sufficient available water resources to meet the demands of water usage within a region. Water scarcity can be a result of two mechanisms: physical (absolute) water scarcity and economic water scarcity. Physical water scarcity rises as a result of inadequate natural water resources to supply a region's demand, while economic water scarcity rises as a result of poor management of the sufficient available water resources [2].

Water usage has been increasing worldwide by about $1 \%$ per year since the 1980 s, driven by a combination of population growth, socio-economic development and changing consumption patterns. Increasing consumption combined with the desertification leads to water and food crises. In the UNCCD report from 2014, it was estimated that over 1 billion people today have no access to water, and the demand will increase by $30 \%$ by 2030 . By 2025, up to 2.4 billion people globally may be living in areas subjected to serious water 
scarcity [3]. Therefore, freshwater is set to become a rare commodity and research is needed to identify sustainable technologies to address the problem of water scarcity.

\subsubsection{Why water from air?}

As an important part of the biosphere water cycle, the atmosphere contains a large amount of water vapor and therefore is a huge renewable freshwater reservoir. It is estimated that 12.9 trillion liters of freshwater in the form of water vapor exists around the Earth making freshwater present at any region inhabited by people on the planet at any point in time.

Landsberg [4] in 1972 has provided the average amount of atmospheric water vapor resources available at Earth's surface in January and July. Lowry [5] concluded that the regions at latitudes north or south of $30^{\circ}$ subject to more than occasional frost, or at frostprone altitudes would not be ideal locations, but populations in these areas usually have adequate water supplies. Other conventional and innovative water sources have physical and economic limitations of site and distribution which are well-known in regions of water scarcity. These regions are often situated in densely populated, developing countries in arid, frost-free zones and include parts of the Caribbean and much of Central America, South America, Africa, the Middle East, and Southern Asia. Hence extracting water from air for arid regions facing water scarcity is a feasible and favorable solution.

Therefore, the idea of harvesting water from the air, which in scientific term also called as Atmospheric Water Vapor Processing (AWVP) was adopted and developed by researchers as a prospective technology to supply freshwater in remote, arid and dry areas especially where there is lack of saline/brackish water. Many companies were manufacturing 
harvesting units also called Atmospheric Water Harvesters (AWH) or Atmospheric Water Generators (AWG) on a commercial scale to tackle the problem of water scarcity.

\subsection{Thesis objective}

Due to the challenges and shortcomings of existing centralized water provision and delivery systems, the idea of decentralized AWH systems has emerged and investigated by several researchers and manufacturers during the last few decades. Decentralized atmospheric water harvesting is a solution to a variety of challenges in common water purification processes. If the input power is supplied from clean energy sources, AWH will be a renewable and sustainable water resource due to two reasons: a) atmospheric humidity is renewed naturally through evaporation from the ocean, and b) AWH process does not generate any side effect or by-products harmful to the environment [6].

A variety of decentralized units producing water from air using solid desiccants, MetalOrganic Frameworks, etc. were explored by scientists and engineers. Most of the systems were based on absorption-desorption based cycles. But very few of them have focused on using liquid desiccants due to either their corrosivity or toxicity of existing liquid desiccants like Calcium Chloride and Lithium Chloride etc. Liquid desiccants have very high moisture uptake at higher humidity levels $(\mathrm{RH}>\sim 50 \%)$ and their potential to absorb water vapor needs to be exploited. With the emergence of new non-toxic and non-corrosive desiccants like potassium formate [7] etc., liquid desiccants can be used for producing water from air. This thesis' objective is to design novel solar energy-based, remotely operable liquid desiccant based system using an aqueous solution of Potassium Formate as the working fluid to absorb moisture and evaluate its performance. 


\section{Literature review}

One of the first works pertaining to water harvesting from the atmosphere was carried out in 1947 by V. Tygarinov in Russia in which a system was developed that consisted of a system of vertical and inclined channels underground to collect water from the atmosphere by cooling moist air to a temperature below its dew point. Since then, rapid progress is being made in the field, which is evident from the report recently published by Omar [8].

There exist several techniques to extract water from moist air and can be broadly classified into (a) condensation of the humid air, where the temperature of humid air is lowered than the dew point by forcing the contact of moist air to a surface colder than dew point causing the water vapor in air to condense, (b) sorbing water vapor using concentrated liquid or solid desiccants, which absorb moisture due to their hygroscopic nature, (c) gas separation using membranes and (d) inducing convection currents in a tall tower structure pushing the humid air to cold high altitude zone where condensation takes place.

Providing safe drinking water to places suffering from water scarcity with affordable cost is the driving force of AWVP techniques [9]. Progress has been made in all the abovementioned techniques using both renewable and non-renewable sources of energy. Suitability of a technique to particular atmospheric conditions was identified, the advantages and disadvantages of each type of system were noted by scientists. The rest of the chapter deals with the details of the most widely used technologies employed for freshwater extraction from air these days and compares those technologies with one another. 


\subsection{Current AWH techniques}

\subsubsection{Fog Harvesting}

Collecting fog drip as a source of water for human needs has a long history and dates to Incas whose civilization thrived in mountainous regions by using the dew collection systems beside rainwater collection. In this method, fog droplets, which are carried by the wind, are collected through a simple surface impaction process by a mesh stretched facing the prevailing wind direction and part of the fog droplets which come into contact with mesh as the air passes through the mesh. Minute fog droplets coalesce and form larger water droplets on the mesh fabric and trickle down into a gutter. The collected water then collected and stored in a reservoir.

In 1969, for the first time, a fog collection project was implemented in South Africa which collected an average of $31 \mathrm{~m}^{3}$ of water per month (about $11 \mathrm{~L} / \mathrm{m}^{2} /$ day) between the period of October 1969 and December 1970 [10]. Since then many fog collection projects were established in Chile, Nepal and many other locations where there is an abundance of fog throughout the year. Fog Quest [11] is a Canadian non-profit organization that has been establishing fog collectors in developing countries since 1987.

Because of the relatively simple design of fog collection systems, their cost of operation and maintenance are minimal and easy to manage. Domen [12] in 2013 has stated that complete human reliance upon fog collection is unrealistic. However, there were certain projects implemented where fog harvesting has been a primary source of water and there are many applications where demand is lower than in most industrial countries and fog water harvesting can become a primary water source [10, 13-15]. 
Optimizing the efficiency of large, passive fog water collectors continues to be a major challenge for the fog water harvesting community [16]. Although fog harvesting though is an economical and sustainable technology, it requires the presence of fog to work and there are only very specific places with favorable fog forming conditions and therefore has limited potential and also not very reliable. Further details regarding current fog collection methods and challenges faced by this technology can be obtained from an article published by Qadir [17] in 2018.

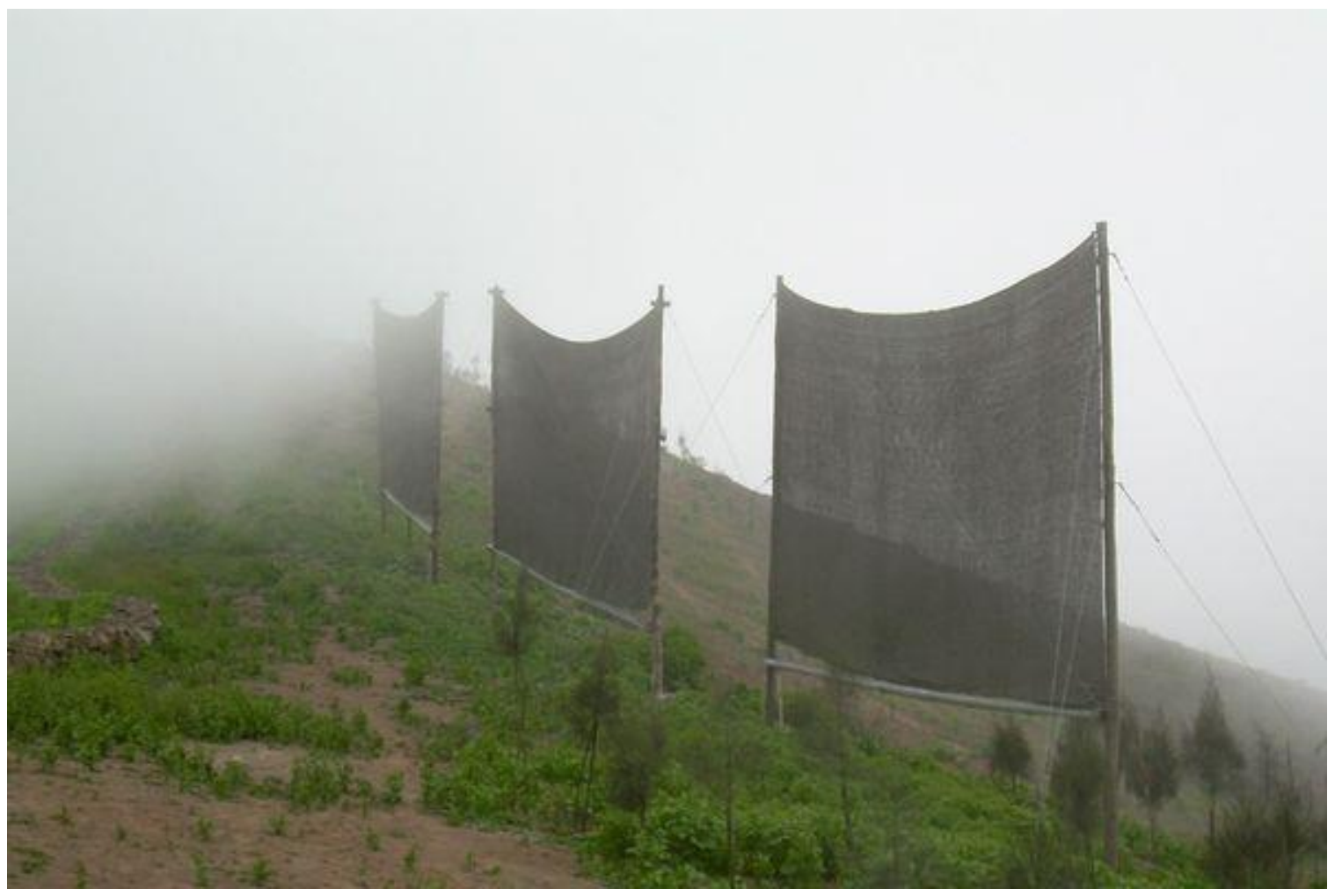

Figure 1 Fog collectors installed in a mountainous region in Chile [18] 


\subsubsection{Heat Pumps}

One of the oldest and commonest ways for extracting the atmospheric humidity is by condensing the water vapor using a cold surface, i.e. the moist air is cooled to a temperature below its dew point following contact with a cold surface. This process involves sensible cooling of moist air from ambient temperature to dew point and then a condensation at the dew point in which there is significant latent heat release. To provide cold surfaces, evaporator coils using either Vapor Compression Refrigeration (VCR) or Vapor absorption Refrigeration (VAR) cycles are employed.

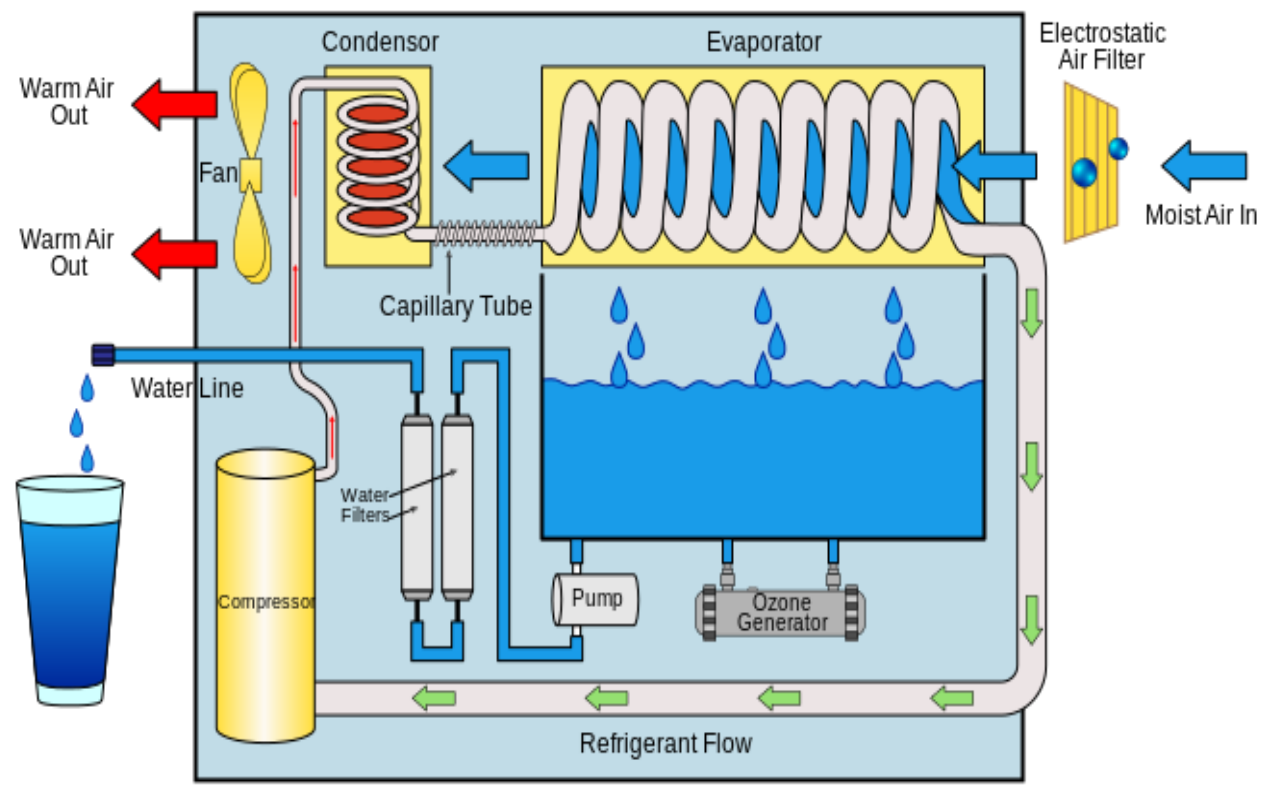

Figure 2 Heat pump generating freshwater from the air [19]

Many organizations sell commercial AWH units either powered by renewable or nonrenewable sources that use heat pumps for generating cold surfaces. Gr8water [20] currently sells AWG's which are based on heat pumps for commercial and residential use. The commercial unit has the capability to generate 13,250 liters of drinking water a day and the residential unit can generate 40 liters of drinking water a day for the average family. 
The Skywater [21] design can produce 1,135 liters of water per day while operating on 416 Watts of power. The Skywater technology uses an adiabatic distillation process to generate the water which uses electrical current that extracts the water from the air. Similarly, there are many other companies that sell units of AWG commercially. AWGs typically have a high market cost ranging from $\$ 300$ to $\$ 16,000$ and require significant additional cost to use due to the electrical power needed to operate [22].

Thermo-Electric Coolers (TECs) have gained prominence and researchers have published some data regarding their performance. Milani [23] in 2010 performed feasibility and psychrometric studies on an AWG that uses TECs using the Peltier-Seebeck effect to predict water generation rates under different operating conditions and commented on the economics of TEC dehumidification. Their device could extract 5.2 liter/day in Sydney, Australia. Rahbar and Esfahani [24] also explored the idea of using TECs to improve the performance of another type of water extraction device: a solar still. Liu [25] in 2017 designed and investigated a TEC which could produce a maximum of 25.1 grams of water each hour with a $0.216 \mathrm{~m}^{2}$ condensation surface and 58.2Watts of input power.

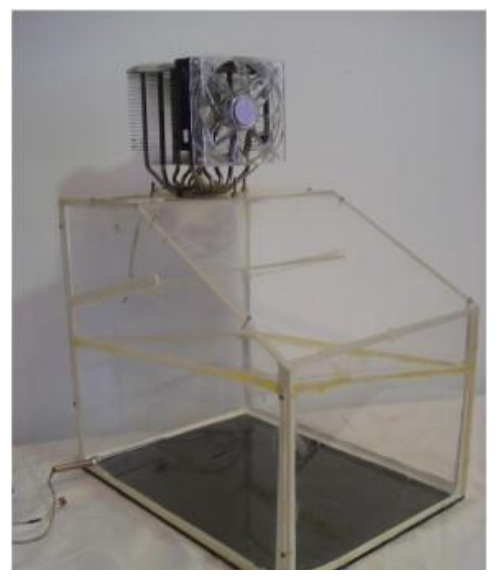

Figure 3 Thermoelectric solar still designed and fabricated by Rahbar and Esfahani [24] 


\subsubsection{Metal-Organic Frameworks}

Metal-Organic Frameworks (MOFs) are crystalline porous solids composed of a threedimensional (3D) network of metal ions held in place by multidentate organic molecules [26]. MOFs are constructed from transition or rare earth metal ions as nodes and multidentate organic ligands containing $\mathrm{O}$ - or N-donors as linkers.

Although MOFs have already been considered in numerous applications-including gas storage, separation, and catalysis, heat pumps and dehumidification the use of MOFs for water harvesting has only recently been proposed. Wang (2017) demonstrated a device based on a porous metal-organic framework (MOF-801, $\left.\left[\mathrm{Zr}_{6} \mathrm{O}_{4}(\mathrm{OH})_{4}(\text { fumarate })_{6}\right]\right)$ that captures water from the atmosphere at ambient conditions by using low-grade heat from natural sunlight at a flux of less than 1 sun (1 kilowatt per square meter). This device can harvest 2.8 liters of water per kilogram of MOF daily at relative humidity levels as low as $20 \%$ and requires no additional input of energy. Continuously harvesting water in a cyclic manner for a 24-hour period with low-grade heat at $1 \mathrm{~kW} / \mathrm{m}^{2}$ can yield $\sim 0.9$ liters $/ \mathrm{m}^{2} /$ day with a 1-mm-thick layer of MOF-801 [27].

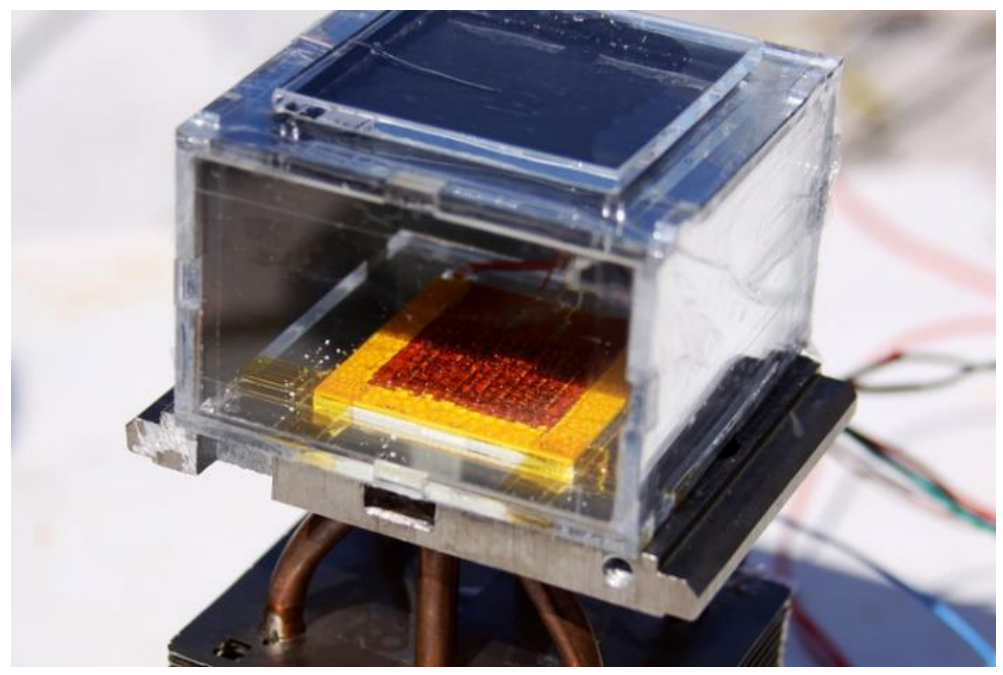

Figure 4 water extraction device utilizing MOFs [26] 


\subsubsection{Desiccant based systems}

Desiccants are the salts that have a high affinity for water vapor. Though desiccants are solid in state, in open air, they absorb moisture and can turn into liquid phase. Based on the state of the desiccant used to absorb moisture, there can be two types of desiccant system, a) Solid desiccant system and b) liquid desiccant system. Below is a review of the work done until now utilizing solid and liquid desiccant systems for the extraction of water from air.

\subsubsection{Solid desiccant systems}

Conventional solid desiccants include silica gel, activated alumina, lithium chloride salt, molecular sieves, titanium silica and synthetic polymers etc.

Solid sorption technology involves two working processes, i.e. in adsorption, water vapor is sorbed by the solid sorbents from the atmosphere with the sorption heat being released; in desorption, the solid sorbents are desorbed by the hot air from solar collectors, and the high temperature and humidity gas are condensed and freshwater is separated out.

In terms of sorbents research, the composite solid sorbents represent the advantages of higher water uptake, economy, and stability. Silica gel, ordered mesoporous silicate and activated carbon are common porous matrixes for composite sorbents; while lithium chloride and calcium chloride are very strong hygroscopic salts with high sorption

performance. Aristov [28] in 1966 performed experiments and recorded water sorption properties on various combinations of water-sorbing salt, $\mathrm{CaCl}_{2}$ impregnated porous media, SWS-1L. However, the composite solid sorbents can't achieve high cycle water uptake mainly due to the small desorption at the low-temperature heat source. Further 
information regarding research on sorbent-salt impregnated composites can be obtained from an article published by Wang [29] in 2017.

Gordeeva [30] performed laboratory tests and concluded that the equilibrium sorption time is as long as $60 \mathrm{~h}$ and the desorption time is $30 \mathrm{~h}$ for solar-driven freshwater production. Ji [31] fabricated a small solar-driven water production unit using a new combination of MCM-41 and $\mathrm{CaCl}_{2}$ composite sorbent and it produced 1.2 liters $/ \mathrm{m}^{2} /$ day. In an effort to utilize minimum components and reduce the cost of the system, Kabeel [32] manufactured a glass pyramid shape with a multi-shelf solar system utilizing cloth and saw wood beds and reported that the freshwater output is $2.5 \mathrm{liter} / \mathrm{m}^{2} / \mathrm{day}$. Wang [33] in 2018 designed both open type concept machine with electric heater as the heat source for removal of moisture and estimated that the system can produce $0.41 \mathrm{liter} / \mathrm{m}^{2}$ of solar collector area, using $2.25 \mathrm{~kg} \mathrm{ACF}-\mathrm{CaCl}_{2}$ composite sorbent, and the semi-open type configuration with improved performance which outputs $2.25 \mathrm{liter} / \mathrm{m}^{2} /$ day using $40.8 \mathrm{~kg}$ sorbents consolidated ACF-LiCl had been investigated.

\subsubsection{Liquid desiccant}

Liquid desiccant includes aqueous solutions of lithium chloride, lithium bromide, calcium chloride and Triethylene Glycol (TEG) and others.

One of the first works relating to water extraction using liquid desiccants was proposed in 1997 by Abualhamayel and Gandhidasan [34]. They proposed to use an aqueous solution of Calcium Chloride to extract freshwater from the humid atmosphere. The unit consists of

a flat, blackened, tilted surface and is covered with single glazing with some air gap to 
facilitate vapor formation. During the night, the strong desiccant flows down as a thin film over the glass cover and due to the absorption of moisture from the ambient, the desiccant becomes diluted. During the daytime, the desiccant flows down as a thin film over the absorber and is heated by incident solar energy. The water that evaporates from the desiccant is condensed on the underside of the glass cover and collected as freshwater. The performance of the unit was computed for the climatic data of August in Dhahran and it was shown that it is possible to obtain about $1.92 \mathrm{liter} / \mathrm{m}^{2} /$ day. Although the concept is very attractive, no experiment was conducted to determine its feasibility.
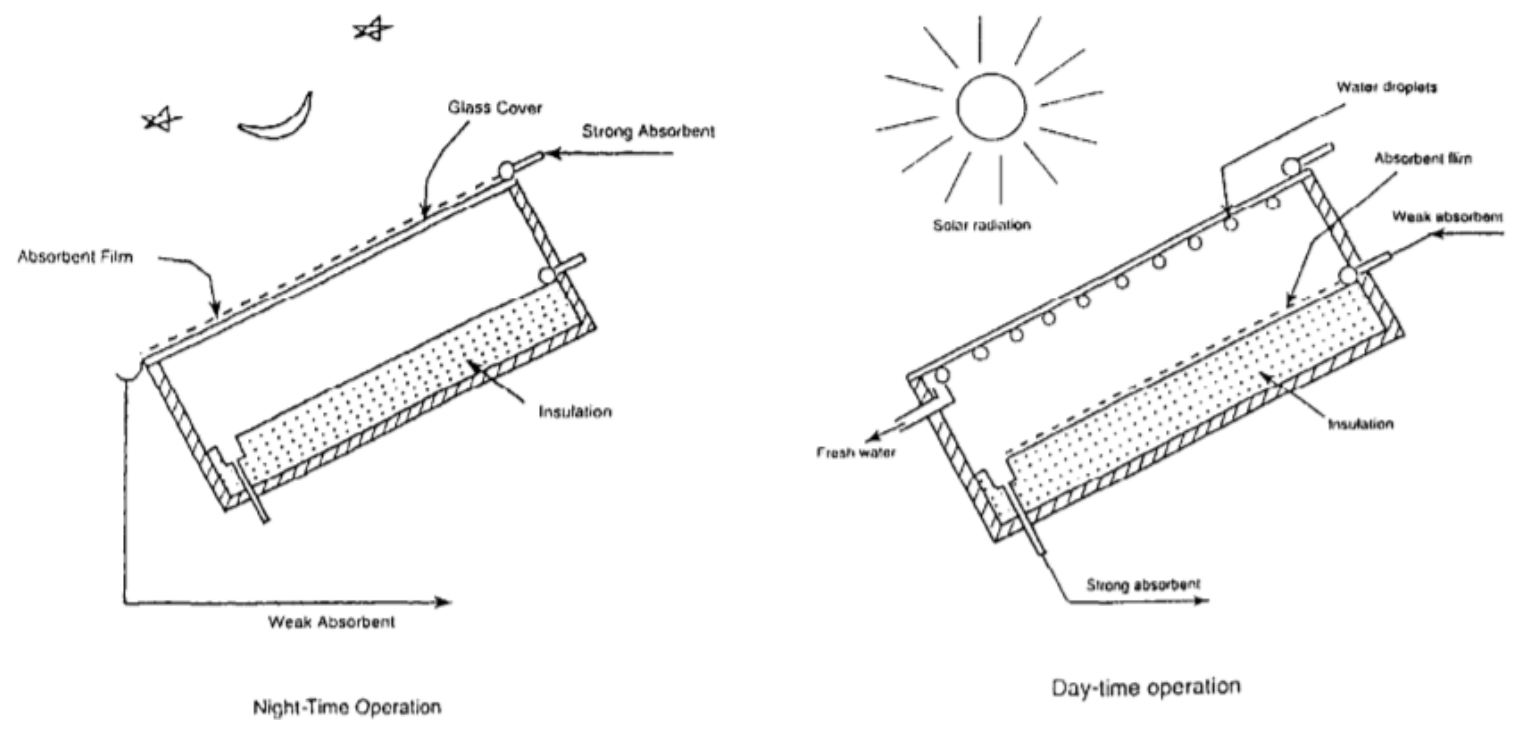

Figure 5 Solar still schematic proposed by Abualhamayel and Gandhidasan [34] Gad [35] in 2001 evaluated the performance of a desiccant/collector system with a thick corrugated layer of blackened cloth to absorb water vapor at night from atmospheric air with subsequent regeneration during the day, using solar energy. Actual recorded results show that the solar operating system can provide about $1.5 \mathrm{liter} / \mathrm{m}^{2} / \mathrm{day}$. System efficiency was defined and values of more than $17 \%$ were recorded. 
Hamed [36] investigated the absorption/regeneration of mass transfer through 13 parallel plates of cloth layers. Cloth layers impregnated with calcium chloride solution were subjected to absorption of water vapor from a flowing air stream with subsequent regeneration by a hot stream. Neither the amount of water absorbed nor desorbed is reported but the experimental measurements were used to determine the mass transfer coefficient as well as Sherwood number. The proposed system is very complex and expensive due to the many components involved in the process.

Gandhidasan [37] in 2010 designed a liquid desiccant system using aqueous calcium chloride solution similar to the one proposed by them in 1997 . The nighttime moisture absorption varied from 1.93 to $2.23 \mathrm{liter} / \mathrm{m}^{2} /$ day with an average value of $2.11 \mathrm{liter} / \mathrm{m}^{2} /$ day. However, the daytime desorption varies from 1.04 to $1.25 \mathrm{liter} / \mathrm{m}^{2}$ depending on the desiccant solution flow rate, with an average value of $1.15 \mathrm{liter} / \mathrm{m}^{2}$. The results clearly indicate that the high humidity is needed for this mode of water collection.

A trapezoidal prism is designed and constructed by Williams [38] in 2015 as a solar collector for desiccant material. The desiccant used was calcium chloride. This desiccant

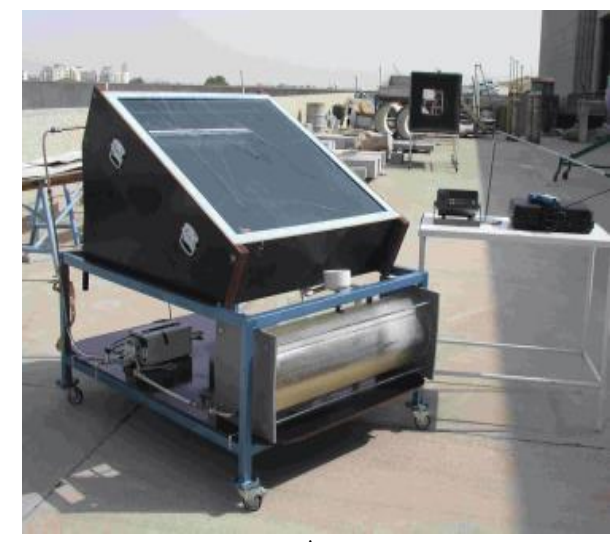

A

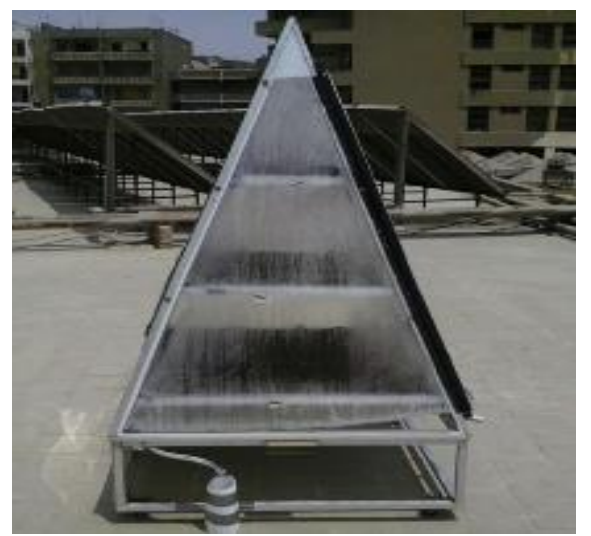

B

Figure 6 A) Solar still developed by Gandhidasan [37] and B) Trapezoidal shelve system developed by Williams [38] 
absorbs the water vapor from humid air then regenerates the absorbed water by solar heat. For cloth bed, the maximum total evaporated water is $2.32 \mathrm{~kg} / \mathrm{m}^{2} /$ day, which is obtained in $\mathrm{CaCl}_{2}$ saturation condition (30\%). For the sand bed, the maximum total evaporated water is $1.24 \mathrm{~kg} / \mathrm{m}^{2} /$ day for $\mathrm{CaCl}_{2}$ saturation condition (30\%). The system efficiency is $29.3 \%$ and $17.8 \%$ for cloth and sand bed, respectively was reported.

\subsection{Comparison of AWH techniques}

\subsubsection{Heat pump versus desiccant based systems}

To produce liquid water through direct cooling, the air should be cooled to the dew point and the cold surface should be colder than the dew point. When low humidity condition occurs, the dew point temperature in arid regions is less than $15^{\circ} \mathrm{C}$ and sometimes maybe as low as $0{ }^{\circ} \mathrm{C}$ in an extremely dry desert climate. Practically, the refrigeration systems start accumulation frost on their evaporator coils when the evaporator surface temperature goes below $5^{\circ} \mathrm{C}$. Frost acts as an insulator inhibiting the heat transfer with the moist air rendering the system to not work. As a result, the refrigeration method is infeasible in the aspect of practical implementation with a huge energy consumption to reduce atmosphere air temperature below its dew point.

On the other hand, desiccants absorb water vapor based on the vapor pressure difference between desiccant and moist air and hence no sensible cooling of air is needed for absorption to happen. Therefore, desiccant systems require less energy to condense water vapor to water. Also, desiccants can absorb moisture even when the dew point is less than $0^{\circ} \mathrm{C}$, unlike direct cooling methods. 
Vapor compression refrigeration cycle AWGs are generally very complex with moving parts and require regular maintenance. Desiccant systems generally use only the fan and pump which are simple mechanical components and usually have a long life. Heat pumps also use refrigerants as the working fluid which has significant Global Warming Potential (GWP). Leaking of refrigerants into the atmosphere is a problem and is a significant factor to discourage the use of heat pumps.

\subsubsection{MOFs versus Desiccants}

It can be observed from Figure 7 that MOFs though have the potential of absorbing moisture at relative humidity levels as low as $10 \%$ and their water uptake saturates at higher relative humidity when compared to desiccants. Most of the salts have an exponential increase in water uptake with an increase in the relative humidity which can be observed from Figure 8.

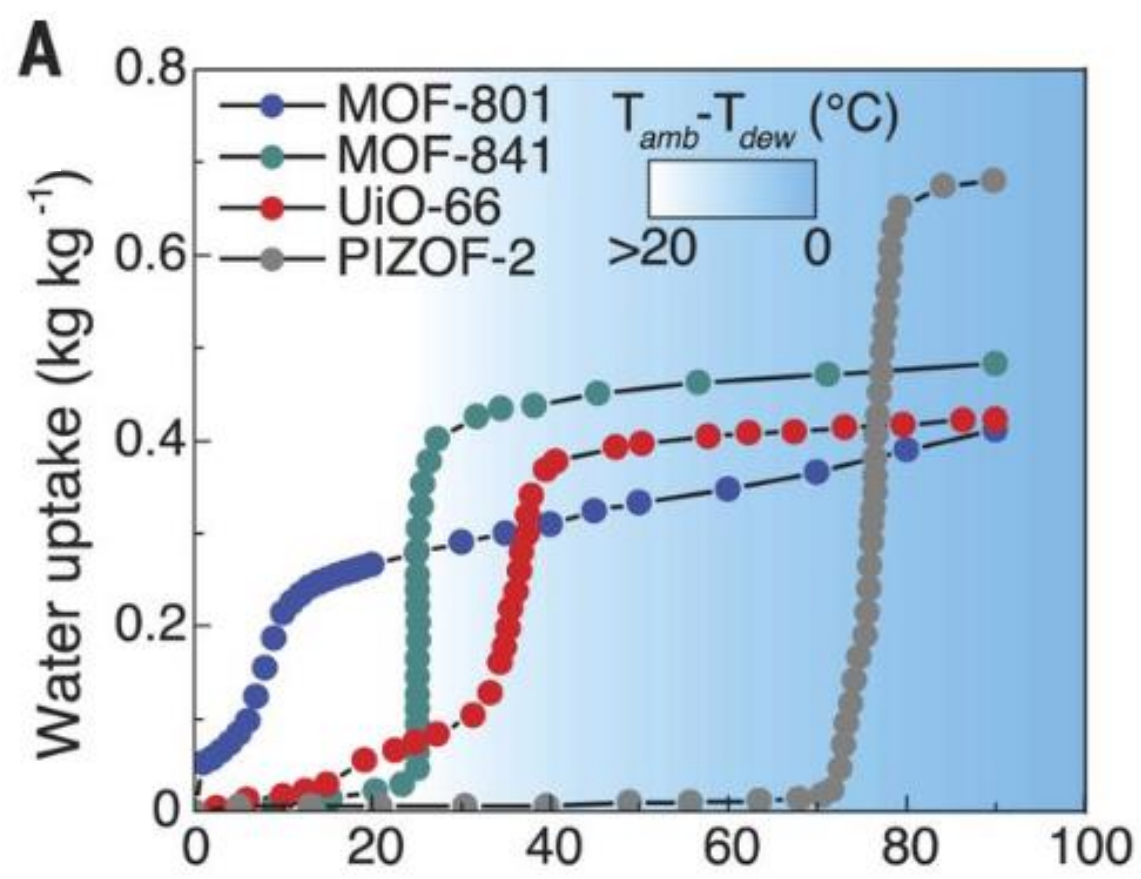

Figure 7 Water absorption isotherms for MOF-801, MOF-841, UiO-66, PIZOF-2 at $25^{\circ} \mathrm{C}$ [27] 


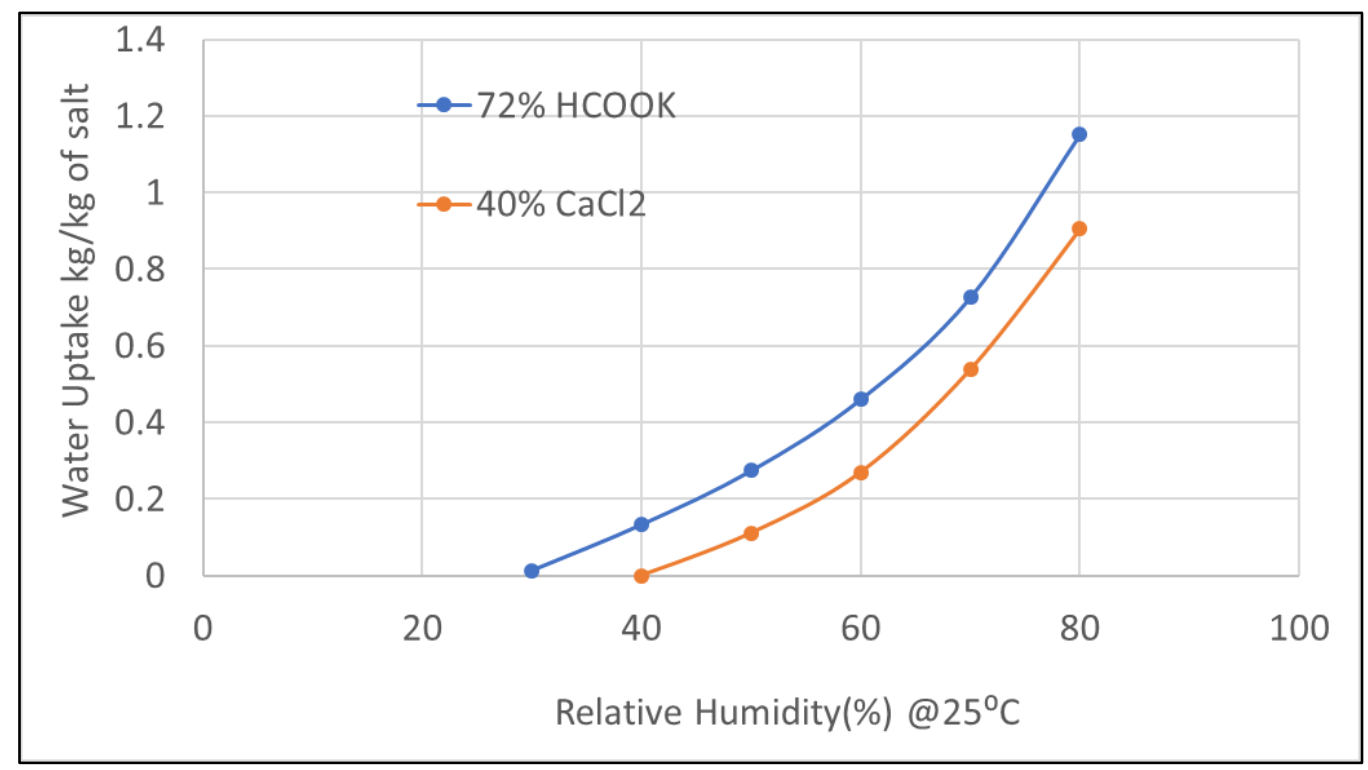

Figure 8 Water absorption isotherms for liquid desiccants,

Potassium formate at 72\% wt. and Calcium Chloride 40\% wt. concentration [39], [40]

\subsubsection{Comparison of solid and liquid desiccant systems}

Both solid and liquid desiccant systems for freshwater extraction have their own advantages and disadvantages. Solid sorption technology is often adopted by scientists for freshwater production due to its advantages of safety, reliability, and energy conservation. Solid desiccant systems also generally have simple systems and are inexpensive if smaller systems are made. Some of the disadvantages of the solid desiccant systems are higher reactivation energy [41] and lower capacity at higher relative humidity because, as salts deliquesce at higher RH thereby hindering the moisture absorption process.

Liquid desiccant systems have several advantages over solid desiccant systems. From the perspective of dehumidification, the pressure drop on the airside through the liquid desiccant mass exchanger is lower than that through the solid desiccant system. Liquid desiccants can be pumped and thus small units can be connected to meet the larger demands and liquid desiccant can be stored for regeneration via some inexpensive energy sources. 
Though liquid desiccant systems are perceived to be unreliable due to corrosion or toxicity of the desiccants. With the advent of newer desiccants like Potassium Formate, the problem of corrosivity and toxicity can be minimized/eliminated. In comparison to the solid desiccant systems, liquid desiccant systems suffer from the shortcoming of the weak heat or mass transfer capacity [41]. Liquid desiccant system's disadvantages are entrainment of desiccant solution in the air, which requires a mist eliminator. When the liquid desiccants are exposed to low RH conditions, they start losing the moisture if circulated through mass exchanger below certain RH and may eventually dry out.

Both solid and liquid systems may lose their potential of absorption after certain operations due to contamination caused by dust or organic vapors and care must be taken to avoid contamination in order to extend the life of the system. Below is the table summarizing the parameters which affect the sustainability, cost of the existing water extraction methods.

Table 1 Summary of the comparison of existing water extraction methods

\begin{tabular}{|c|c|c|c|}
\hline Technology & Eco-friendly & Non-corrosive & Material cost \\
\hline Fog harvesting & & كـ & \\
\hline Heat pump & & & - \\
\hline MOF-801 & & & ( \\
\hline Solid desiccant & כ & & $\mathrm{c}$ \\
\hline Liquid desiccant & & $\begin{array}{l}\text { Potassium formate } \\
\text { Conventional desiccants }\end{array}$ & \\
\hline
\end{tabular}




\section{Proposal and design procedure}

\subsection{Proposed system}

It can be concluded from the literature review that liquid desiccant systems have the advantage of low power consuming components, and their potential has not been explored by researchers much for freshwater extraction from the air. Through this thesis, it is proposed to develop an atmospheric water harvesting system based on liquid desiccant with packed bed dehumidifier as a mass exchanger for the absorption of moisture from the air during the night, when the relative humidity is the highest. Evacuated Tube Collector (ETC) equipped with Compound Parabolic Concentrators (CPC) is the source of low-grade heat to boil the low concentration liquid desiccant and drive off water during daytime. An air-cooled heat exchanger is employed to condense the generated steam to liquid water. For simplicity, the system was segregated into two components i) a mass exchange system where the components of the system absorb moisture and ii) a solar concentrating system where the components of the system remove absorbed moisture. The proposed moisture absorption and desorption process are shown in Figures 9 and 10.

\section{Concentrator}

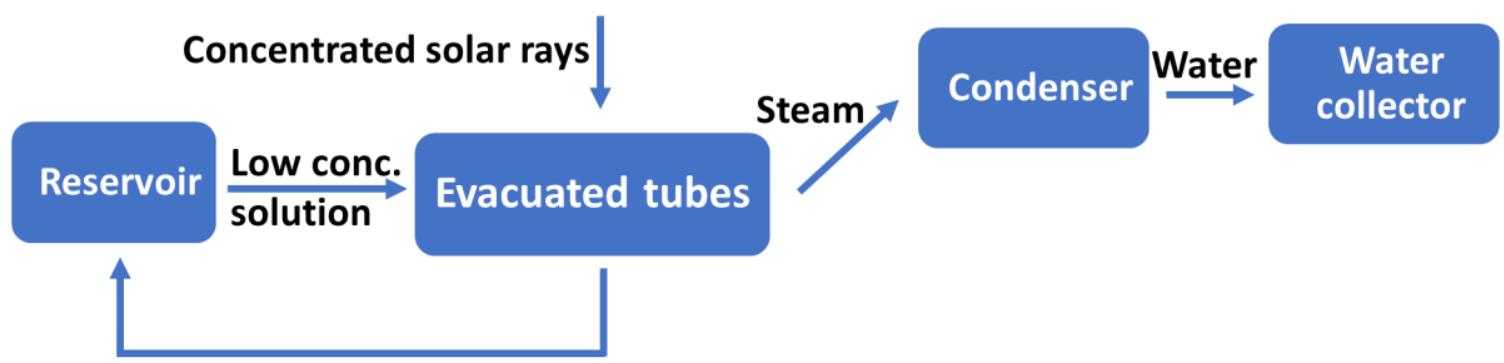

High conc. solution

Figure 9 Proposed moisture desorption process 


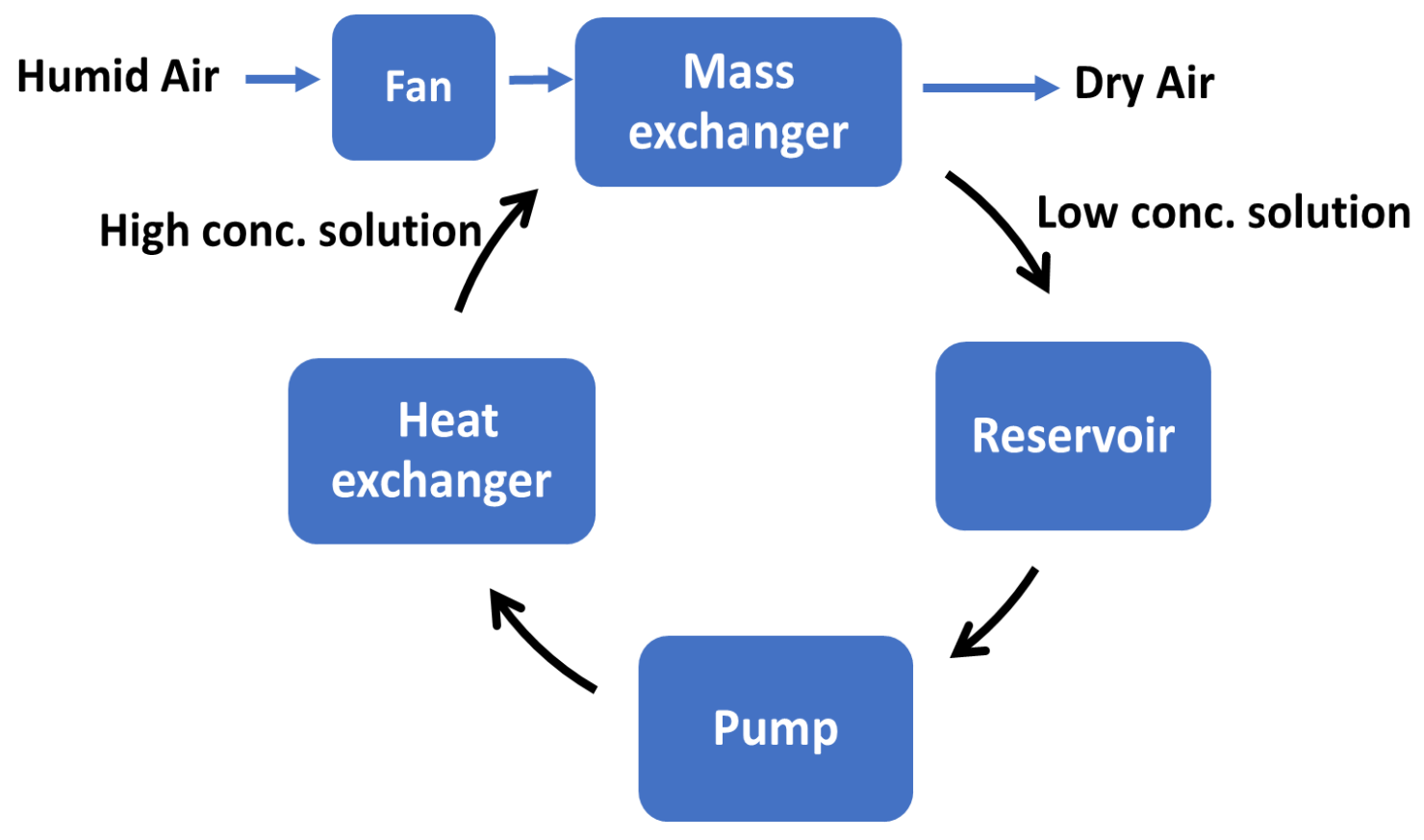

Figure 10 Proposed moisture absorption process

The rest of this chapter describes the procedure followed for the design of mass exchange and solar concentrating systems.

\subsection{Solar concentrating system}

Solar energy is clean, renewable and is naturally available in abundance in most parts of arid regions of the world. Due to the rapid depletion of existing non-renewable energy resources and concerns about climate change, the use of solar energy as an alternative source of energy for a variety of applications has been on the rise. There are various systems that use solar thermal energy as a driving force, such as solar cooling systems, solar water heating and solar-assisted cooling and heating systems. Each system needs a critical temperature for its operation. For our particular application, it was decided to remove the moisture by boiling off the absorbed moisture from the liquid desiccant and then condensing the generated steam. Since the liquid that needs to be boiled will be a 
concentrated solution of a desiccant, the maximum temperature expected to reach ranges from 120-140 degree Celsius. The expected temperature is considered high for a solarbased system and a proper system needs to be designed to reach such high temperatures.

To obtain the required temperatures using solar energy, flat-plate collectors are commonly used. Some attention has also been given to using concentrator collectors, specifically CPCs due to certain advantages explained in section 3.3.2

\subsubsection{Compound parabolic concentrators}

$\mathrm{CPC}$ are non-imaging concentrators and their potential for solar energy concentration was pointed out by Winston and Hinterberger (1975). One of the first works explaining the theory and working principles of various CPC was conducted by Rabl [42], in 1976.

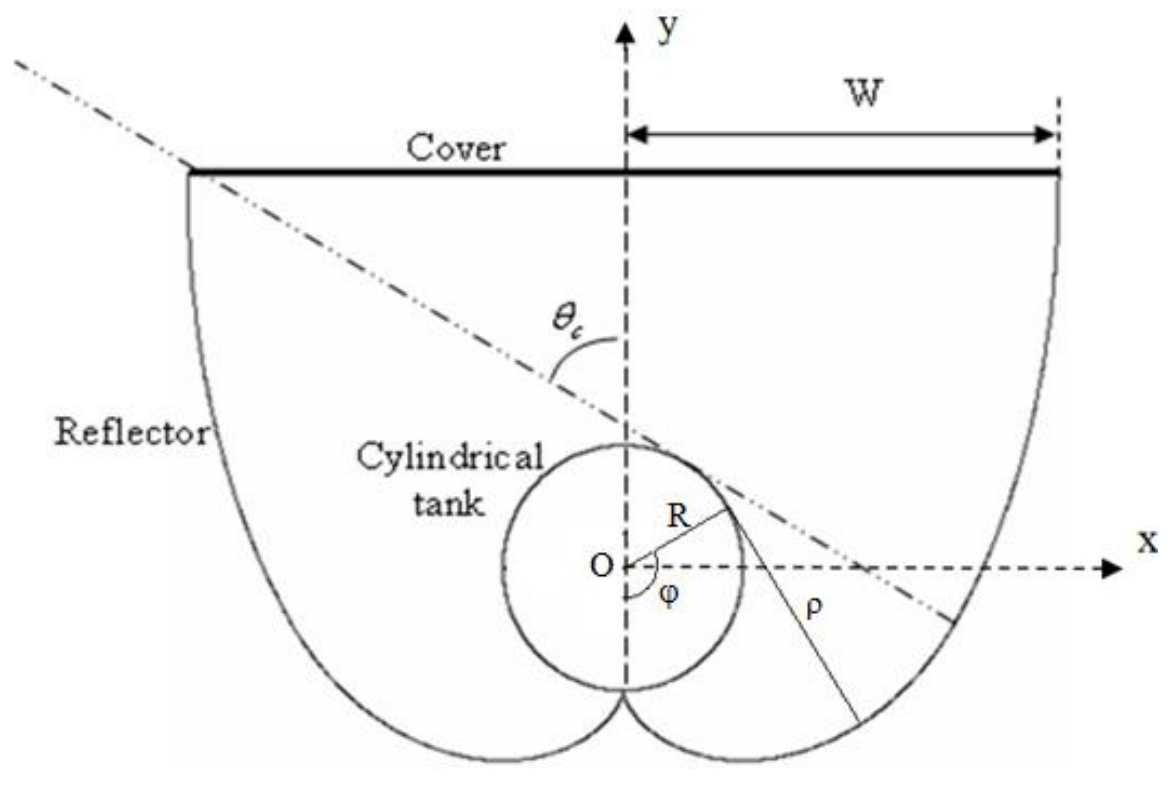

Figure 11 Schematic of a CPC [43] 
As seen from the Figure 11, CPC is made of two halves of parabola with closely located focal points and their axes inclined to each other, such that rays incident within the angle between the two axes (acceptance angle of the CPC) are reflected with single or multiple reflections towards the region between the two focal points and get concentrated in that region. Thus, CPCs can accept incoming radiation over a relatively wide range of angles. By using multiple internal reflections, any radiation that is entering the aperture, within the collector acceptance angle eventually, finds its way to the absorber surface located at the bottom of the collector. As the upper part of a CPC contribute little due to a steep angle of incidence to the radiation reaching the absorber, they are usually truncated thus forming a shorter version of the CPC [42].

\subsubsection{Evacuated tube collectors}

Evacuated tube collectors also known as ETCs, absorb incident solar energy and convert it to usable heat. Evacuated tube collectors are a way in which heat loss to the environment, through the vacuum between the two glass layers it forms an efficient isolation mechanism to keep heat inside the collector pipes, and thereby convection heat losses have been reduced. Since two flat sheets of glass are normally not strong enough to withstand a vacuum, the vacuum is rather created between two concentric tubes and also cylindricalshaped absorbers have the advantage of utilizing full surface for energy absorption, unlike flat absorber where the backside must be insulated properly to prevent/minimize heat loss. The inner tube of the cylindrical is coated with a thermal absorbent, which converts the incident light energy to heat. Life of the vacuum varies from collector to collector, anywhere from 5 years to 15 years. Flat-plate collectors are generally more efficient than ETC in full sunshine conditions. However, the energy output of flat-plate collectors is 
reduced slightly more than evacuated tube collectors in cloudy or extremely cold conditions [44].

Due to the advantages of the non-tracking advantage of CPCs and heat loss minimization in ETCs, the combination of them has been chosen as the system for boiling the liquid desiccant during the day utilizing solar radiation.

\subsubsection{Mechanism of heat transfer in combined CPC and ETC}

At first, the solar radiation incident on the $\mathrm{CPC}$ is concentrated by the reflecting profile to the surface absorber of the inner evacuated tube mainly through reflection, refraction and transmission of solar radiation. The absorbing coating absorbs the majority of the radiation. The absorbed heat is transferred to the working fluid in the tube. Then the other part of the energy incident on the inner tube will dissipate to the environment by radiation.

Due to ease of construction and long lengths of ETCs, it is a general practice to use heat pipes to transfer the heat absorbed by the tubes to working fluid. In order to minimize the energy losses due to the presence of heat pipes, in our system, the tubes were directly filled with the working fluid 


\subsubsection{Designing the reflector}

The first step in the process of designing a reflector is to generate the 2D CPC profile. The 2D geometry of a CPC with tubular absorber in the coordinate system is given by equations 1,2 and 3 [42].

$$
\begin{gathered}
x=R \sin \phi-\rho \cos \phi \\
y=-R \cos \phi-\rho \sin \phi \\
\frac{\rho}{R}=-\left[\begin{array}{cc}
\phi & \text { for } 0 \leq \phi 0.5 \pi+\theta_{a} \\
\frac{0.5 \pi+\theta_{a}+\phi-\cos \left(\phi-\theta_{a}\right)}{1+\sin \left(\phi-\theta_{a}\right)} & \text { for } 0.5 \pi+\theta_{a}<\phi \leq 1.5 \pi-\theta_{a}
\end{array}\right.
\end{gathered}
$$

where $\theta_{a}$ is the acceptance angle of the CPC, $R$ is the radius of the tubular absorber, $\theta_{a}$ is the acceptance angle.

The parameters that define the design of a CPC are concentration ratio, truncation height, collector diameter. The ideal concentration ratio of a CPC is related to the acceptance angle $\theta_{a}$ as shown in equation 4 .

$$
C R=\frac{1}{\sin \left(\frac{\theta_{a}}{2}\right)}
$$

Hence it can be concluded that concentration ratio increases with decreasing acceptance angle. Higher acceptance angles result in a longer duration of acceptance of the solar radiation by the CPC. The maximum acceptance angle is $180^{\circ}$, where the concentrator can absorb solar radiation for 12 hours. An appropriate value of the acceptance angle was selected based on the desired maximum width and height of the CPC. CPCs are often truncated to reduce the cost and overall height of the concentrator because the upper 
portions contribute far less to concentrating the solar radiation. Truncation allows to reduce the height and width of the CPC and increase the acceptance angle of the reflector, but the concentration factors reduce. The value of the concentration ratio after truncation is calculated by equation 5 .

$$
C R_{\text {truncated }}=\frac{W}{2 \pi r}
$$

Where $W$ is the width of the opening of the reflector after truncation and $r$ is the inner radius of the ETC.

It is a common practice to tilt the reflectors to maximize the absorption of solar radiation. To further maximize the absorption the reflectors can be tracked in such a way that solar radiation is always normal to the reflector. But tracking the sun requires the addition of moving components and consumes power. So, the reflectors were tilted by a fixed angle equal to the latitude of the location and are placed facing south.

The total solar energy incident on the coating layer in each reflector, $Q_{c p c}$, is given by equation 6.

$$
Q_{c p c}=q_{r} * \eta_{c p c} * A_{c p c}
$$

where $q_{r}$ is solar irradiance perpendicular to the reflector, $A_{c p c}$ is the lighting area of reflector and $\eta_{c p c}$ is the system optical efficiency of reflector.

The optical efficiency of a truncated CPC is a function of optical properties of both reflector and absorber, angle of incidence of the incoming rays and acceptance angle of the CPC after and before truncation. For truncated reflectors, it can be concluded from observing the results of the ray-tracing simulations performed by wang that even after truncation, the 
efficiency of the CPC is highest when the angle of incidence is within the half acceptance angle before truncation. The efficiency of the CPC for incidence angle greater than the half acceptance angle, the efficiency is very low and the contribution of the radiation to the heating of the fluid can be neglected. If the angle of incidence is less than the half acceptance angle of the CPC, the optical efficiency is almost constant and is calculated by equation 7.

$$
\eta_{c p c}=\rho^{<n>} \tau_{e} \tau_{d} \alpha_{i} p f_{r e f}
$$

where the $\rho$ is reflectivity of CPC plate, $\tau_{e}$ is transmissivity of the evacuated tube, $\alpha_{i}$ is absorptivity of selective coating, $\tau_{d}$ is the dust stratification factor of the evacuated tube and $\langle n\rangle$ is the average number of reflections and it is assumed to be equal to 1 because the concentration ratio of the simplified CPC is relatively low. The gap loss coefficient, $p$ of simplified CPC is given by the engineering calculation formula given in equation 8 .

$$
p=1-\frac{g}{\pi d}
$$

Where $d$ is the inner diameter of the ETC and $g$ is the minimum gap between the reflector and inner surface of the tube.

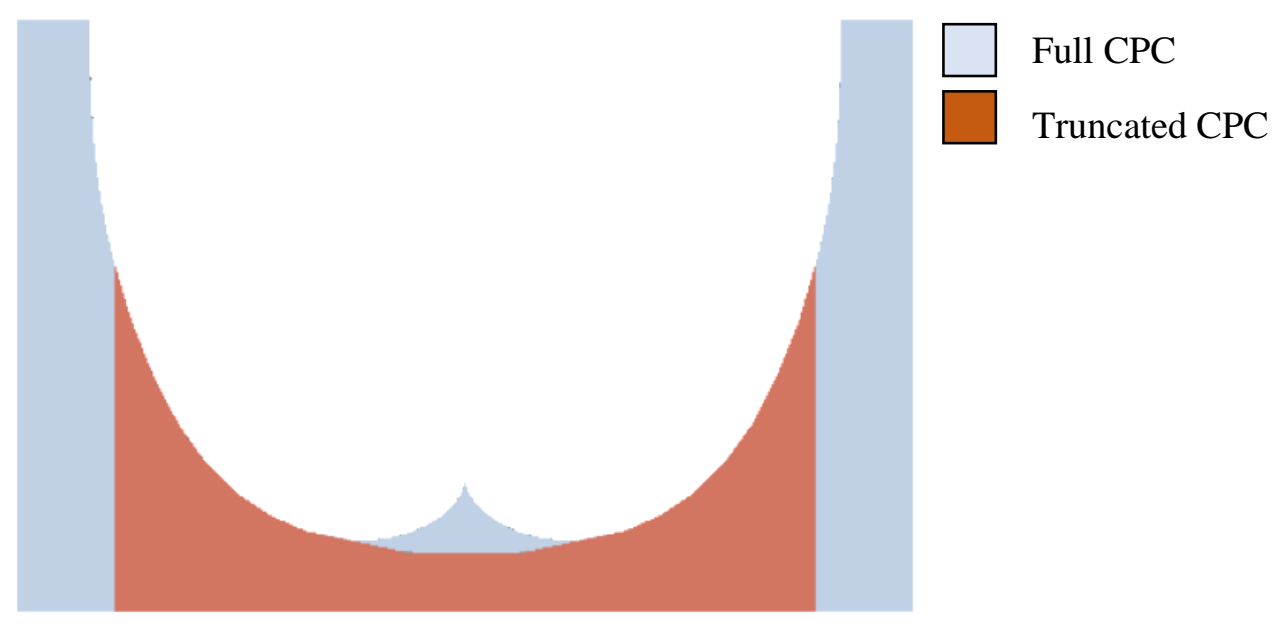

Figure $12 \mathrm{CPC}$ cross section after and before truncation 
To improve the manufacturability and thereby reduce the cost of the reflector part of the involute part of the base has been replaced with a flat curve as seen in Figure 13.

Table 2 Geometrical and optical parameters of CPC

\begin{tabular}{|c|c|}
\hline Parameter & Value \\
\hline Outer radius $\mathrm{R}(\mathrm{mm})$ & 29 \\
\hline Inner radius $\mathrm{r}(\mathrm{mm})$ & $24 \mathrm{~mm}$ \\
\hline ETC length (m) & 1.8 \\
\hline$\theta_{a}\left({ }^{0}\right)$ & 60 \\
\hline Ideal $C R$ & 2 \\
\hline$\theta_{t}\left({ }^{0}\right)$ & 89 \\
\hline$C R_{\text {truncated }}$ & 1.32 \\
\hline Height of the reflector, $H(\mathrm{~mm})$ & 101 \\
\hline Width of the reflector, $W$ (inch) & 202 \\
\hline Length of the reflector, $L(\mathrm{~m})$ & 1.2 \\
\hline Reflector material & Polished stainless steel \\
\hline$\tau e$ & 0.90 \\
\hline$\alpha_{i}$ & 0.92 \\
\hline$\tau_{d}$ & 0.90 \\
\hline$P$ & 0.80 \\
\hline$P$ & 0.81 \\
\hline$\eta_{c p c}(\%)$ & 50 \\
\hline
\end{tabular}




\subsubsection{Condenser}

In order to condense the steam generated by ETCs and produce clean distilled water during the daytime operation, an appropriately sized condenser was placed in tandem to the ETCs. A standard air-cooled heat exchanger along with a fan can be used to condense the steam.

\subsubsection{Performance metrics of solar concentrating system}

The parameter defining the performance of the solar concentrating system is thermal efficiency. If $Q_{r}$ is the total incident solar irradiance during the day in $\mathrm{kJ} / \mathrm{m}^{2}$ and which is expended in providing the specific heat and latent heat to the liquid desiccant in the ETCs, neglecting the specific heat of the glass, thermal efficiency of the solar concentrating system is defined as the ratio of the combined specific and latent heat to the incident energy and is calculated by the equation 9 .

$$
\eta_{\text {sytem }}=\frac{m_{l} * C_{p} * \Delta T+m_{w} * h_{f g}}{n * Q_{r} * A_{c}} * 100
$$

Where $m_{l}$ is the total mass of liquid desiccant in the tubes at the start of the day in kg., $C_{p}$ is the specific heat of the liquid desiccant corresponding to the initial concentration of the liquid desiccant in $\mathrm{kJ} / \mathrm{kg}-\mathrm{K}, \Delta T$ is the temperature difference required to bring the liquid desiccant to boiling point in Kelvin, $m_{w}$ is the total mass of water produced in $\mathrm{kg}, h_{f g}$ is the specific latent heat of vaporization of water in $\mathrm{kJ} / \mathrm{kg}, \mathrm{n}$ is the total number of ETCs in the system.

The other relevant performance metric for the concentration system is the Coefficient of Performance or COP, which is defined as the ratio of output and input and calculated by equation 10. 


$$
C O P=\frac{m_{w} * h_{f g}}{Q_{r}+t * I * V}
$$

Where $t$ is the total duration for which condenser fan is turned on, $I$ is the current drawn by fan and $V$ is the voltage applied across the fan.

With the design process of solar concentration established and performance parameters defined for its performance, we proceeded with the design and performance metrics of the mass exchange system

\subsection{Mass exchange system}

The components of a typical liquid desiccant mass exchange system are liquid desiccant, dehumidifier, heat exchanger, reservoir, solution pump and fan. The design procedure of the mass exchange system has been explained below.

\subsubsection{Choosing a desiccant}

It is evident from the literature review that the main drawback of a liquid desiccant system (LDS) is toxicity and corrosive nature of the aqueous solution of the desiccants. For the production of freshwater for drinking purposes, it is absolutely necessary to use a non-toxic liquid desiccant or at least prevent the mixing of desiccant and output fresh water. For economic reasons, it is important to have non-corrosive liquid desiccants. So, the selection of appropriate desiccants is one of the crucial steps in the design of a low-cost and efficient mass exchanger.

Desiccant's thermophysical and colligative properties also play vital role in deciding performance and operating parameters of the mass exchange and solar concentrating system such as the maximum temperature that can be attained during boiling, minimum 
ambient temperature for the moisture absorption process to happen, maximum moisture uptake per day, rate of moisture absorption in the cycle and etc. The most important thermophysical properties of the desiccant which need to be considered in our design are density, vapor pressure and crystallization temperature which are functions of both concentration of salt in the solution and temperature of the solution.

Liquid desiccants are used extensively in dehumidification and air conditioning applications and from the literature review, it can be observed that researchers have used some liquid desiccants for freshwater extraction from water. Some of the ubiquitous liquid desiccants used in the field of dehumidification and/or AWVP equipment are Lithium Chloride and Calcium Chloride. Of the above desiccants, Calcium chloride is the most economical and is non-toxic but is very corrosive, and also has inferior properties pertaining to the mass exchange process.

A new addition to the list of desiccants is a chemically stable, non-corrosive, non-toxic and environmentally friendly Potassium Formate (HCOOK) liquid desiccant solution. Potassium Formate solution is being widely used for deicing the airport runways due to its eco-friendly nature and non-corrosive properties [45]. Very little work has been done on potassium formate in the dehumidification field and no work until now has been done for extraction of water from air utilizing potassium formate.

The thermophysical and colligative properties of potassium formate are superior to calcium chloride and comparable with lithium chloride. Due to the non-toxic, non-corrosive and eco-friendly nature of potassium formate when compared with lithium chloride, potassium formate has been chosen as a desiccant for our equipment. 


\subsubsection{Thermophysical and colligative properties of potassium formate}

The important thermo-physical and colligative properties that need to be considered are vapor pressure, recrystallization temperature, specific heat, density which are all function of the instantaneous concentration of salt in the solution and temperature of the solution. The calculation procedure of vapor pressure and density given by James [39] is explained below.

Calculation of density as a function of temperature and concentration of salt:

$\rho_{\text {sol }}=1004-1191 T_{\text {sol }}-0.002 T_{\text {sol }}^{2}+5.62 X_{\text {sol }}+0.02616 X_{\text {sol }}^{2}-0.005975 T_{\text {sol }} X_{\text {sol }}$

Where $T_{\text {sol }}$ is the solution temperature in degree Celsius and $X_{\text {sol }}$ is the mass percentage concentration of salt in the solution.

Vapor pressure:

Vapor pressure of aqueous solution of potassium formate $P_{\text {sol }}$ is given by equation 12 .

$$
P_{\text {sol }}=X_{m} * \exp (\gamma) * \exp \left(P_{\mathrm{H}_{2} \mathrm{O}}\right)
$$

The molecular weight of the desiccant solution, $X_{m}$ and is calculated using equation $13, \gamma$ is the activity coefficient of water and is calculated using equation 14 and $P_{\mathrm{H}_{2} \mathrm{O}}$ is the vapor pressure of the water in the desiccant solution at a given temperature in Pascals and is calculated using equation 18 .

$$
X_{m}=\frac{1}{\left(1+\frac{M_{\mathrm{H}_{2} \mathrm{O}} * X^{\prime}}{M_{\mathrm{CHKO}_{2}} \times X_{\mathrm{H}_{2} \mathrm{O}}}\right)}
$$


Where $\mathrm{X}^{\prime}$ is the desiccant solution mass concentration as a percentage and $M_{\mathrm{H}_{2} \mathrm{O}}$ and $\mathrm{M}_{\mathrm{CHKO}_{2}}$ are the molecular weight of water vapor and potassium formate and equal to, $18.015 \mathrm{~g} / \mathrm{mol}$. and $84.11 \mathrm{~g} / \mathrm{mol}$. respectively.

$$
\gamma=A *(1-Z)^{2} *\left(1+4.19 * Z *\left(Z-\frac{2}{3}\right)\right)
$$

where $\mathrm{A}, \mathrm{B}$ and $\mathrm{Z}$ are constants, calculated using equations 15,16 and 17 respectively.

$$
\begin{gathered}
A=-2.08-\frac{1336}{T_{\text {sol }, K}} \\
B=-3.42-\frac{1039}{T_{\text {sol }, K}} \\
Z=\frac{A * X_{m}}{\left(A * X_{m}+B *\left(1-X_{m}\right)\right)} \\
P_{H_{2} O}=73.649-\left(\frac{7258.2}{T_{s o l, K}}\right)-7.3037 * \ln T_{\text {sol,K }}+0.0000041653 *\left(T_{\text {sol }, K}\right)^{2}
\end{gathered}
$$

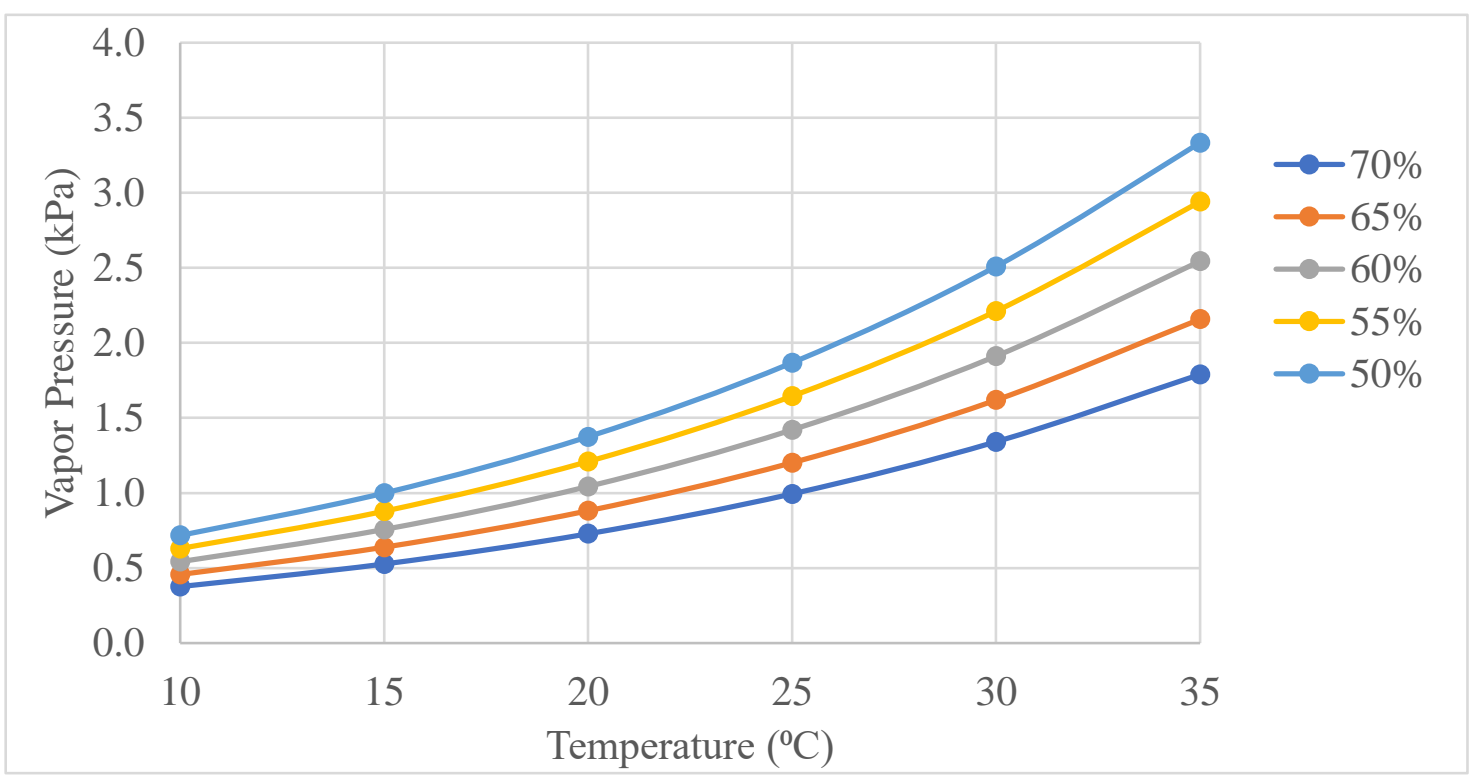

Figure 13 Vapor pressure graphs for potassium formate at various mass concentrations and temperature [39] 
When reverse mass transfer process takes place in the dehumidifier, the density of the solution increases and the solution loses enough moisture, it may crystallize, which is undesirable. The density at which the solution crystallizes is a function of only the temperature of the solution itself and is called true crystallization temperature (TCT). Initially, with an increase in the concentration of the solution (and thereby density), the TCT drops. But, TCT increases when the density is further increased from $1.35 \mathrm{~g} / \mathrm{cm}^{3}$.

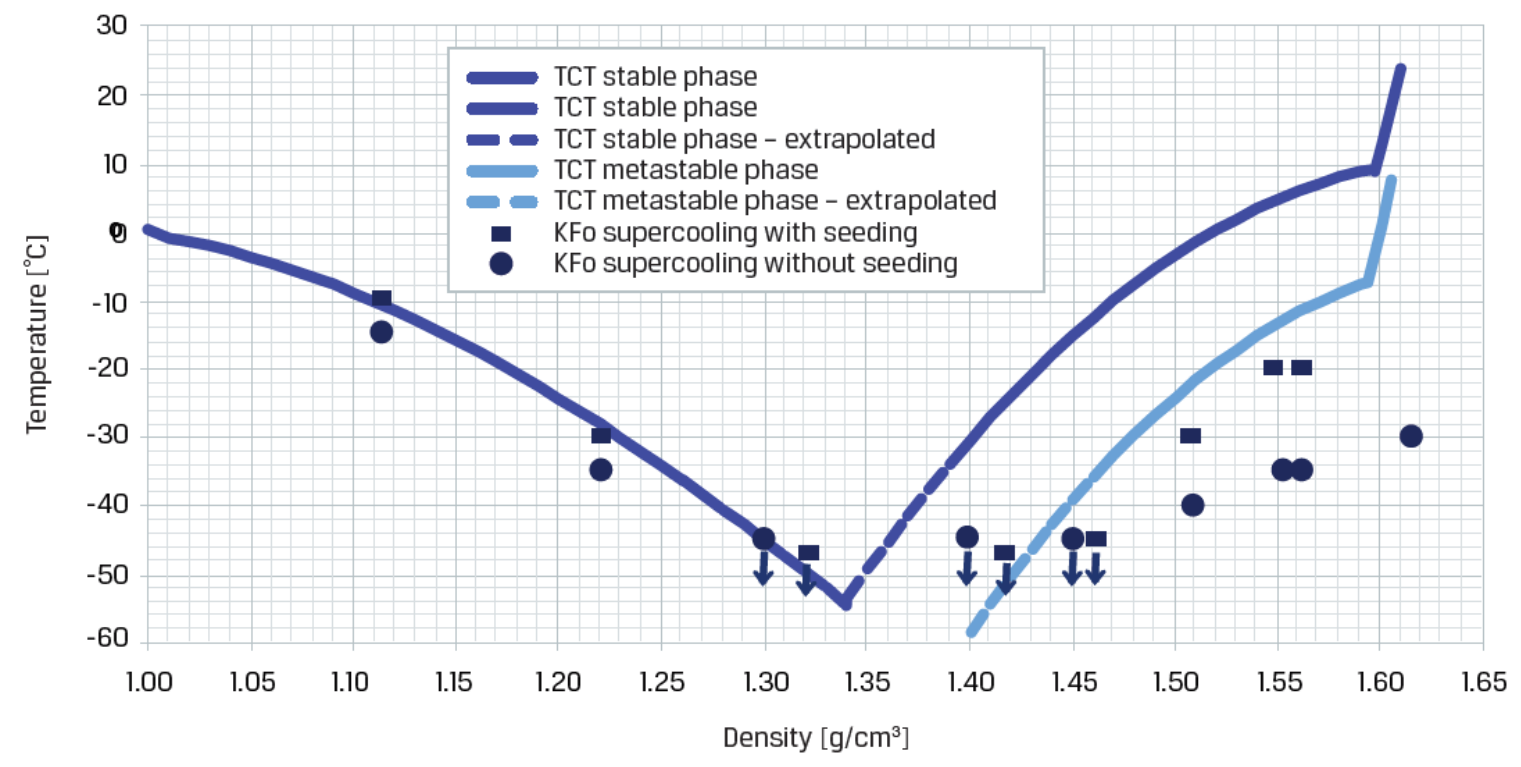

Figure 14 Variation of TCT with the density of potassium formate [46]

From the graph, it can be noted that, if the maximum density that can be attained in the whole water extraction process is $<1.5 \mathrm{~g} / \mathrm{cm}^{3}$, the solution will not saturate/crystallize until $0^{\circ} \mathrm{C}$. It can be observed that if density crosses $1.6 \mathrm{~g} / \mathrm{cm}^{3}$ the crystallization temperature rises rapidly with an increase in density and therefore the maximum allowable density is chosen between $1.5-1.55 \mathrm{~g} / \mathrm{cm}^{3}$.

For the liquid desiccant to absorb moisture, the vapor pressure of the moist air should be greater than the vapor pressure exerted by the liquid desiccant. The driving force for the process is the vapor pressure difference. If the vapor pressure of liquid desiccant is greater than the air it comes into contact with, the solution loses moisture i.e. reverse mass transfer 
and might crystallize eventually. Hence figure 15 and figure 16 helps the designer in deciding the operating points for the mass exchange process and identifying when would the system reach equilibrium and when would reverse mass transfer take place

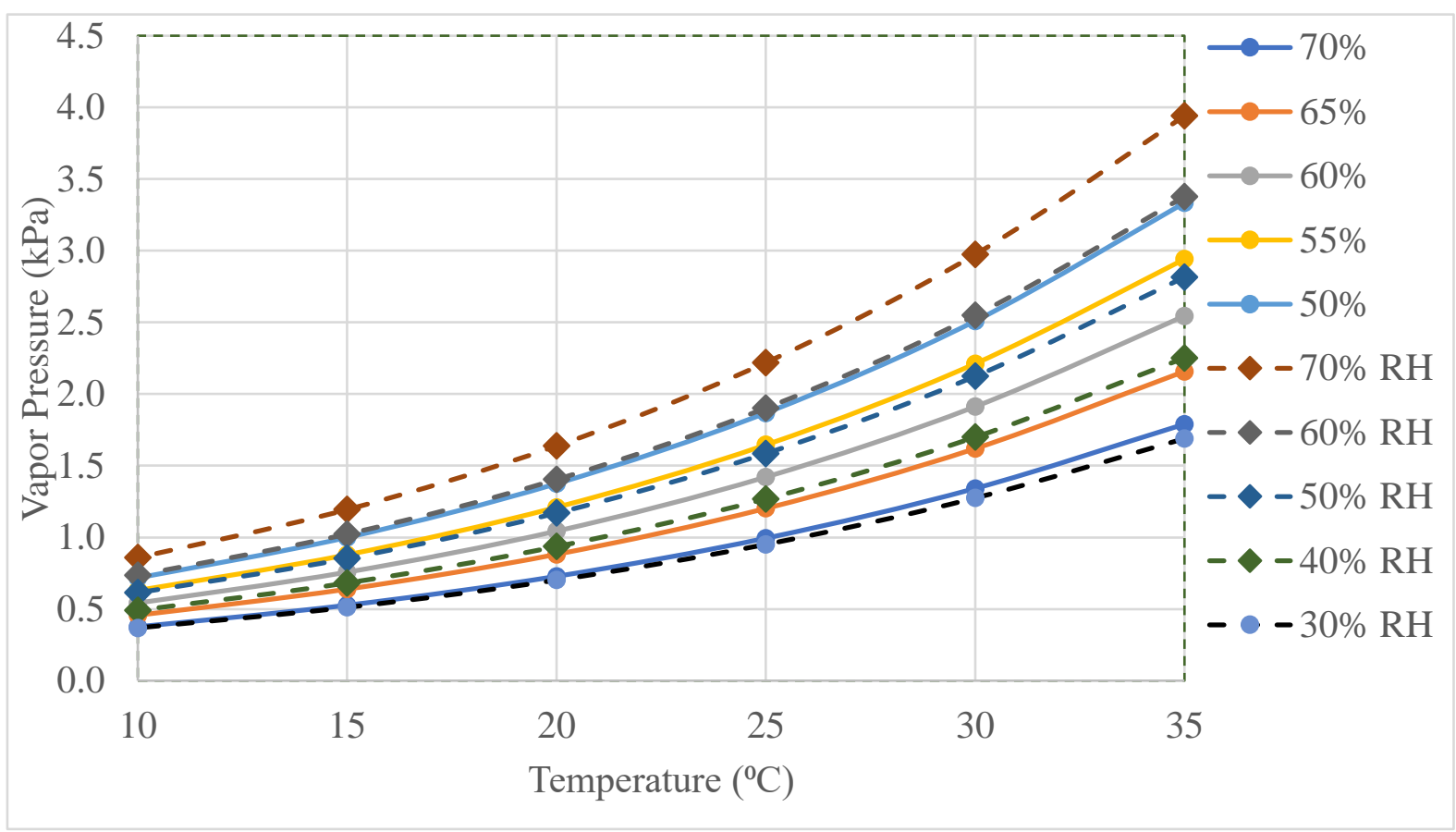

Figure 15 RH equilibrium chart for potassium formate at various concentrations [39]

\subsubsection{Psychrometric properties}

The two important psychrometric properties of moist air which need to be considered while designing a mass exchanger and that decide the uptake of moisture and rate of moisture uptake are water vapor content in the air, also known as absolute humidity and vapor pressure of moist air.

Then the actual vapor pressure exerted by water vapor in moist air, $P_{w v}$ can be calculated from equation 19.

$$
P_{w v}=P_{H_{2} O} * R H
$$


Humidity ratio $(\omega)$ is the quantity that defines the amount of water vapor contained in the air and can be stated as kg of vapor/kg of dry air. The following calculation for water vapor concentration in air apply at ground level and is calculated using equation 20 .

$$
\omega=\frac{0.62198 * P_{w v}}{P-P_{w v}}
$$

Where $P$ is the total atmospheric pressure.

\subsubsection{Designing a mass exchange system}

Liquid desiccant systems are heavily employed in air conditioning applications for dehumidification application and typically consists of a combination of an absorber and a regenerator. In the absorber, the moisture from humid air is absorbed by the liquid desiccant and reduces its concentration. The concentration level of the desiccant solution is restored in a regenerator using hot air to remove the absorbed moisture. But in the current water extraction system, the regeneration is carried out during the day by the solar concentrating system. Hence, the current system needs only an absorber and its design procedure is explained below.

An absorber/dehumidifier removes moisture from the air using the strong affinity of desiccants for water vapor. The direction and speed of moisture removal are dependent on the vapor pressure difference between air and liquid desiccant. The moisture removal from air occurs as long as the vapor pressure of the liquid desiccant is lower than the air. Water absorption leads to the generation of heat caused by the condensation of water vapor present in the air onto the desiccant. Hence the process of moisture absorption by desiccant is both mass transfer (- driven by vapor pressure difference) and heat transfer (- driven by 
temperature difference). Several theories were developed to explain the process of mass transfer. Some of them are film theory, penetration theory and surface renewal theory and can be obtained from [47].

Finned-tube surface, coil-type absorber, spray tower, and packed tower are some of the commonly used dehumidifying units for Liquid desiccant Air Conditioning (LDAC). Of these types of dehumidifiers, packed bed columns are the most widely used due to their ease of construction, cost and favoring the use of non-corrosive elements. Due to the heat generated during the mass transfer process, the temperature of the solution rises and thereby increases its vapor pressure, making the mass transfer process slow. Hence, an internal cooler is often employed and is called an internally cooled dehumidifier. The dehumidifiers without a cooling system are called adiabatic dehumidifiers. For our particular application, due to the additional power required for cooling, an adiabatic dehumidifier is used.
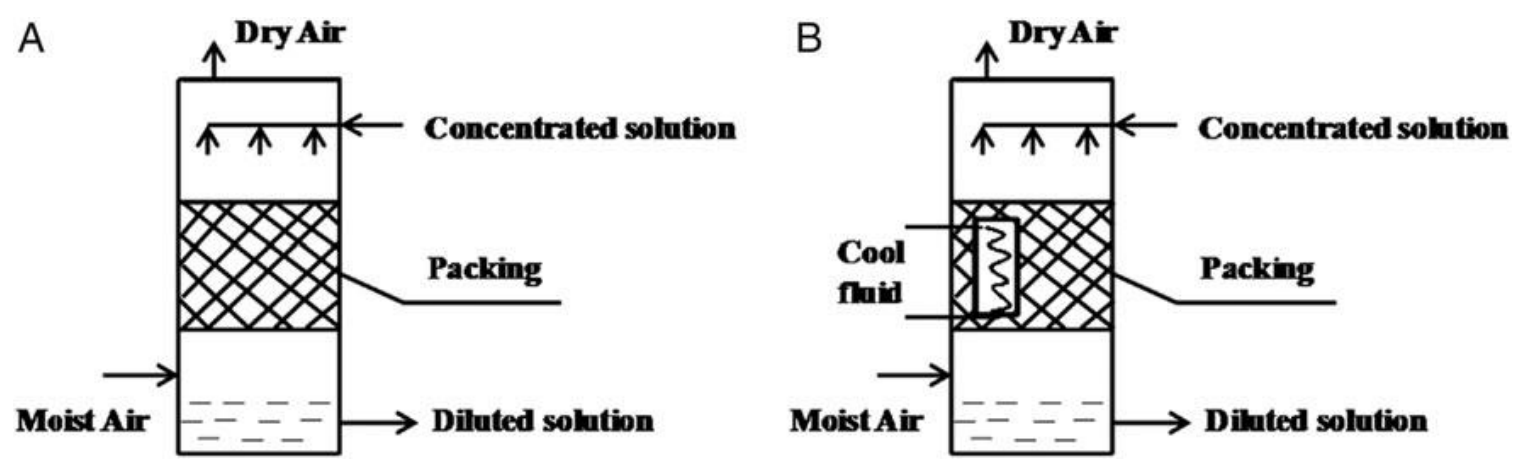

Figure 16 Types of dehumidifiers A) Adiabatic dehumidifier B) Internally cooled dehumidifier [48]

The flow configuration within the dehumidifier determines the contact area and the process of interaction between desiccant and inlet air. There can be three general types of flow configurations in the dehumidifier, a) counter-current flow where the solution stream 
and air stream flow in opposite directions b) parallel flow configuration where air and solution stream flow in the same direction and c) cross-flow configuration where the air stream and solution stream are perpendicular to each other. Liu [49] performed an analysis on an internally cooled dehumidifier and concluded that the performance of counter flow is best followed by cross-flow, while the performance of parallel flow is not optimum. Hence counterflow configuration has been chosen for mass exchanger design.

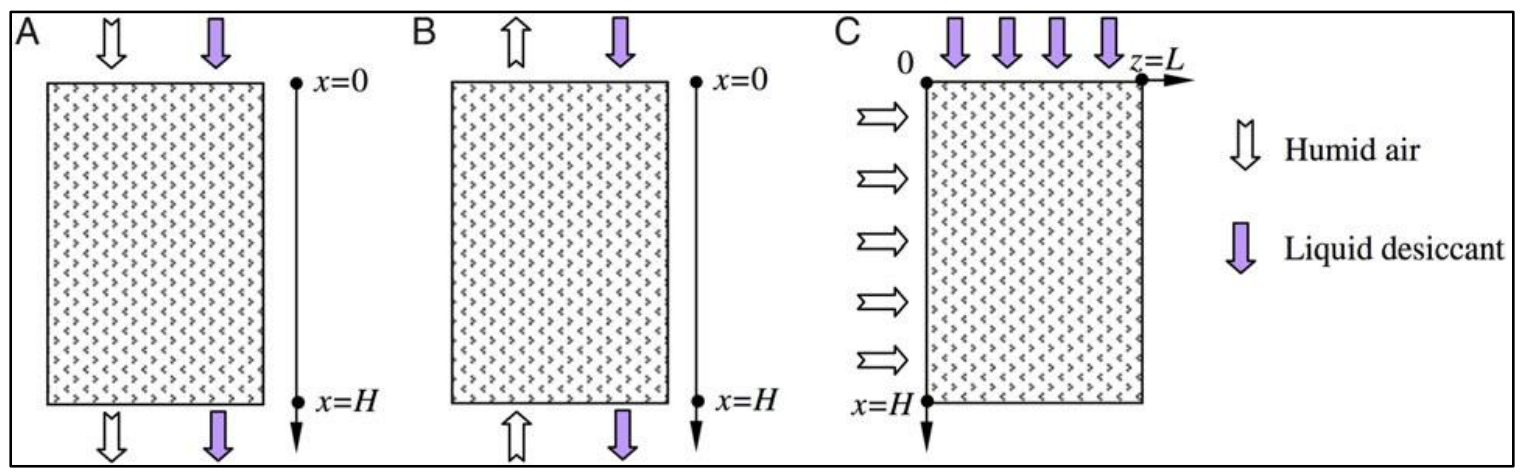

Figure 17 Various flow configurations in a dehumidifier A) Parallel flow dehumidifier B) Counter flow dehumidifier and C) Cross flow dehumidifier [49]

Packing material is needed in mass exchanger for mixing of humid air and liquid desiccant. There are two types of packaging material available a) structured packing and b) random packing based on their configuration. Regular packing increases the performance of the dehumidifier by providing low-pressure drop for the air stream and is easy to install as compared with random packing. It also reduces the liquid desiccant resistance in the dehumidification unit. Random packing material cannot adjust to the variation in liquid desiccant flows and results in uneven distribution of the desiccant solution over the surface of the packing material, which reduces the performance of the dehumidification system. However, regular packing is costlier than random packing. Some common examples of random packing material include ceramic, plastic, stainless steel, polypropylene palls, Raschig rings whereas structured packing material is either gauze type or sheet type. 
Structured packing materials are generally made of stainless steel-corrugated orifice plates, Celdek pads, etc. Void ratio and packing thickness are important parameters. Airflow resistance depends on the void ratio, which decreases with the increase in the void ratio [46]. In order to reduce the cost of the whole equipment and to keep the weight of the equipment to a minimum, plastic scrubber used for dishwashing was used as the pack

A

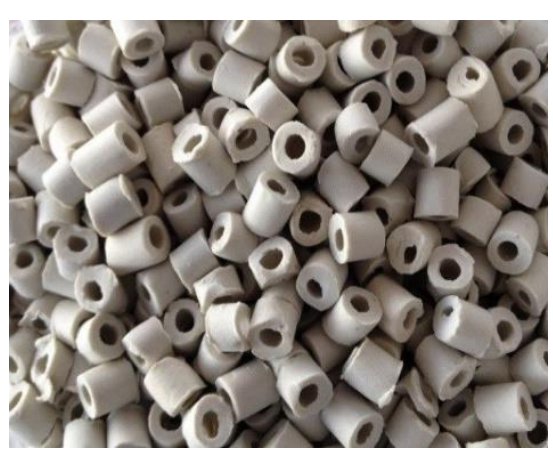

B

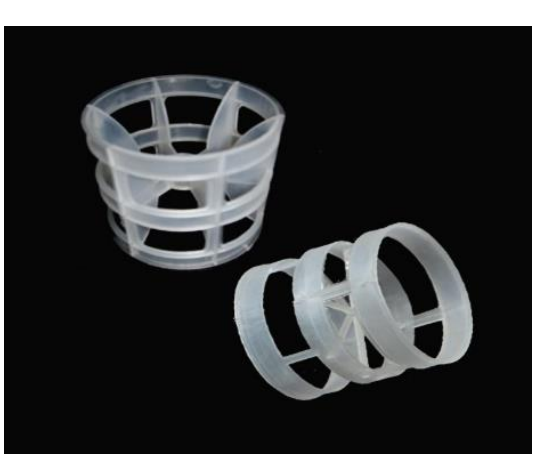

C

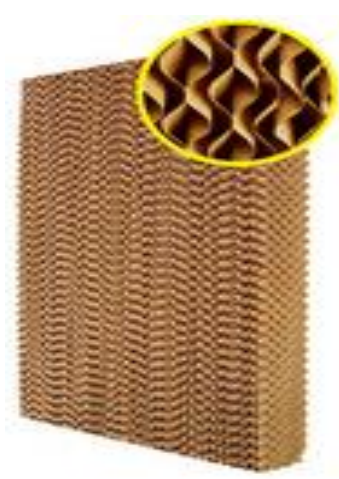

Figure 18 A) Ceramic raschig rings and B) Polypropylene palls used in random packing and C) Celdek pads used in structure packing

The performance of the mass exchanger is measured in terms of effectiveness. The mass transfer effectiveness can be defined as the ratio of actual change in air humidity ratio across the packed absorber divided by the maximum possible change and given by equation 21.

$$
\varepsilon=\frac{\omega_{\text {in }}-\omega_{\text {out }}}{\omega_{\text {in }}-\omega_{\text {eq }}}
$$

Where, $\omega_{e q}$ the equilibrium humidity ratio, which is a function of the inlet desiccant solution temperature and concentration, $\omega_{\text {out }}$ is outlet air's humidity ratio and $\omega_{\text {in }}$ is inlet air's absolute humidity. 
A commercial shower head has been used as the solution distributor for even distribution of the desiccant solution over packing material. Due to the absence of correlations between mass transfer rate and geometrical parameters of the dehumidifier with potassium formate as the mass transfer medium, the height and amount of packing material were obtained by trial and error basis. The following table provides the details of the mass exchange system

Table 3 Design parameters of the mass exchanger

\begin{tabular}{ll}
\hline Parameter & Value \\
\hline Inner diameter (mm) & 152 \\
Total height of mass exchanger (m) & 1.37 \\
Packing height (m) & 1.22 \\
Packing material & Plastic scrubs \\
Diameter of the showerhead (mm) & 101 \\
Capacity of reservoir (Liter) & 10 \\
Volume flow rate of air (CFM) & 50 \\
Volume flow rate of desiccant (ml/s) & 50 \\
\hline
\end{tabular}




\section{Experimental setup}

In order to investigate the feasibility of the proposed system in Chapter 3, a prototype was designed and built to extract a liter of water per day from the air. The remainder of the chapter deals with the prototype design, technical details of the components and sensors used.

4.2 Schematic and operation of the proposed system

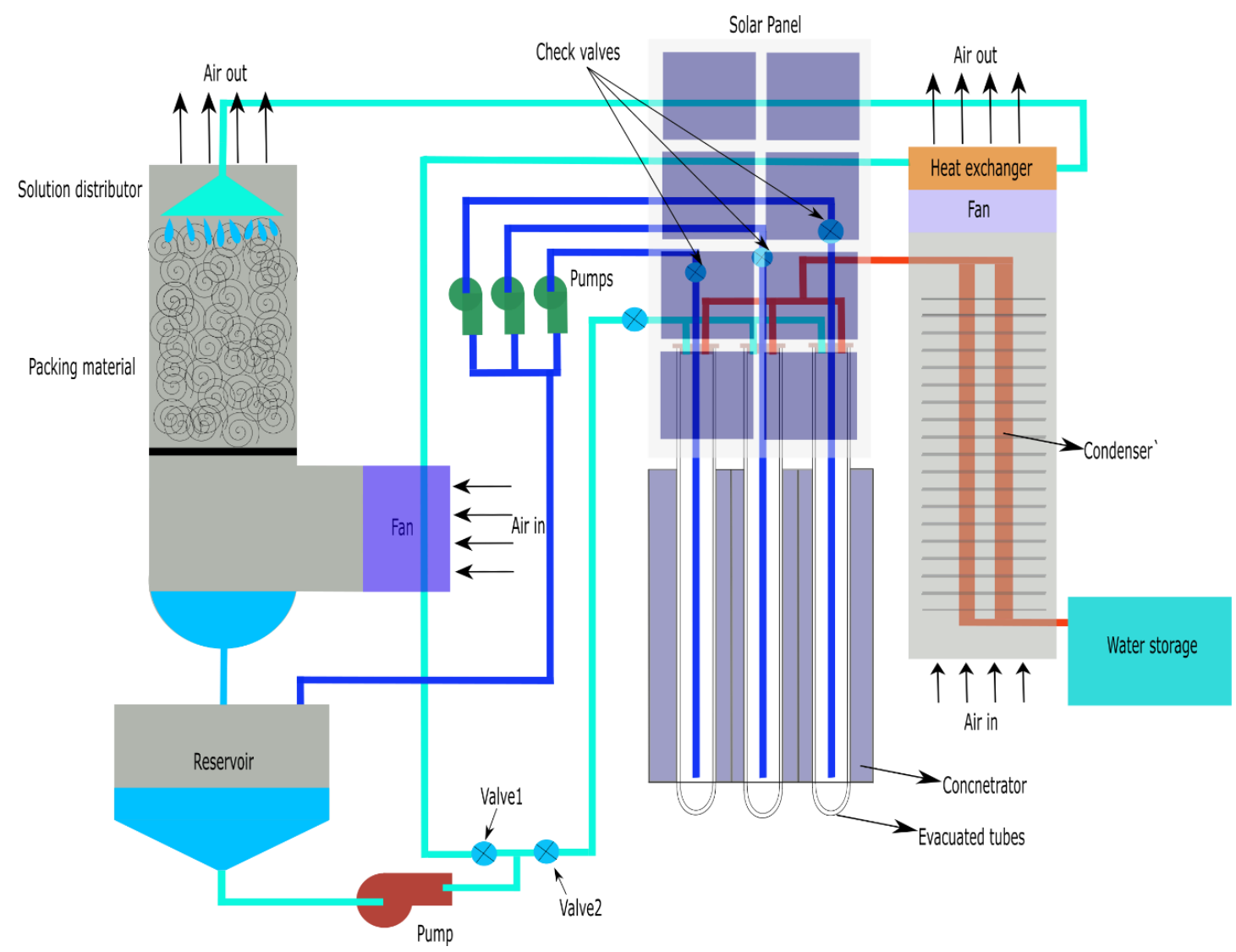

Figure 19 Schematic of the proposed liquid desiccant based AWH

Figure 19 shows the components and their layout of the proposed system. The sequence of operation of the prototype is explained below. At the start of the day, the reservoir is filled 
with a low concentration desiccant solution. The valve2 as shown in Figure 19 leading to evacuated tubes opens and the solution is pumped into the evacuated tubes. After filling the tubes with the solution, the valve 2 is closed. As the day proceeds, the evacuated tubes convert incident light energy to heat and heats up the desiccant solution within them and ultimately leads to the boiling of the liquid. When the liquid inside the tubes starts boiling, generated steam enters into a condenser as shown in Figure 19. The steam condenses in the heat exchanger and collects in a water storage container. The loss of water from the desiccant solution leads to an increase in the concentration of desiccant in the solution. The desorption process ends when there is no more sun to generate heat. The hot, high concentration solution from the tubes is pumped out into the reservoir to start cooling off the solution. Before the start of the mass exchange process, the fans for secondary heat exchanger and the mass exchanger turn on, valve1, as shown in Figure 19 leading to the heat exchanger, opens and the liquid desiccant is pumped out of the reservoir. The liquid passes through the heat exchanger where it cools down to ambient temperature. The liquid then sprinkles evenly onto the packing material though a solution distributor and collected into the reservoir. This cycle continues for the whole night, as long as the relative humidity is high enough to carry out moisture absorption. At the start of the day, due to moisture absorption, the solution has returned to low concentration ready for the desorption of absorbed moisture. The description of the components used in building the prototype system is given below.

\subsubsection{Evacuated tubes}


Three numbers of Apricus' ET10 evacuated tubes as seen in figure 20 were used along with the aluminum heat transfer fins to promote even temperature distribution all along the tubes.

\subsubsection{Concentrator}

It is absolutely necessary for the concentrator to be low cost, moisture-resistant and durable. Hence plastic and stainless steel materials are used for fabricating the concentrating system. Three $1.22 \mathrm{~m}$ long simplified CPC profile reflectors were fabricated with $0.1 \mathrm{~mm}$ thick mirror finish stainless steel sheets as shown in Figure 20. The reflectors were attached to four CPC profile shaped $19 \mathrm{~mm}$ thick HDPE sheets spaced at $0.3 \mathrm{~m}$ apart from each other using self-tapping screws. Each of the concentrators for the tubes was attached to each other using $8 \mathrm{~mm}$ thick HDPE sheets and attached using self-tapping screws. The CPC shape of the HDPE sheets were made using CNC water jet cutting.

\subsubsection{Solution pump}

A pump is required for pumping liquid desiccant to both evacuated tubes and into mass exchanger during day and night respectively. A $640 \mathrm{GPH}, 12 \mathrm{~V}$ DC brushless pump has been used for this purpose.

\subsubsection{Condenser}

A car radiator has been used as a condenser and is placed within a six-inch PVC pipe to direct the airflow. Semi-circle shaped baffles made of acrylic sheets were inserted at regular intervals and sealed with metallic tape as seen in Figure 21 to increase the heatcarrying capacity of air flowing through the radiator. A fan is placed at the top of the PVC pipe to facilitate airflow in counterflow configuration. 


\subsubsection{Heat exchanger}

During the mass exchange process at night, due to the heat released during the vapor condensation process, the liquid desiccant solution and air heat up and the vapor pressure of the desiccant solution rises for the same concentration level. If the solution is not cooled down, the mass exchange process stops after a certain time and also may even lead to reverse mass transfer if the desiccant solution is allowed to cycle. Hence, a heat exchanger is placed right before the solution distributor to cool down the solution to near ambient temperature. An air-cooled aluminum CPU cooler has been used as the heat exchanger and is placed above the fan used for condenser.

\subsubsection{Fan}

A mass exchanger needs a fan to pump air into it from which the moisture is removed. Since the pressure drop across the packing material is usually high, a powerful fan is required to achieve the desired airflow rate. A $110 \mathrm{~V}$ AC fan with a maximum flow rate of $400 \mathrm{CFM}$ has been used to pump air into mass exchanger as seen in Figure 21. The fan consumes $67 \mathrm{~W}$ at the highest air flow rate.

\subsubsection{Solar panel and battery}

A 160 Watt solar panel accompanied with 100 Ah 12 V Dc battery was mounted over the prototype to power the mass exchange components during nighttime. 


\subsubsection{Miscellaneous}

A 10-liter polyethylene plastic tank has been used as a reservoir. 12V DC self-priming pumps are used for transferring liquid desiccant from tubes to the reservoir. The caps for ETCs were made of HDPE plastic and the tubes passing through the ETCs need to withstand high temperatures and should not react with potassium formate solution while it is boiling and hence FEP plastic has been used which can withstand temperature as high as $200^{\circ} \mathrm{C}$. A 2.5 -liter stainless steel container with clear lid was used as a water storage chamber.

\subsubsection{Prototype}

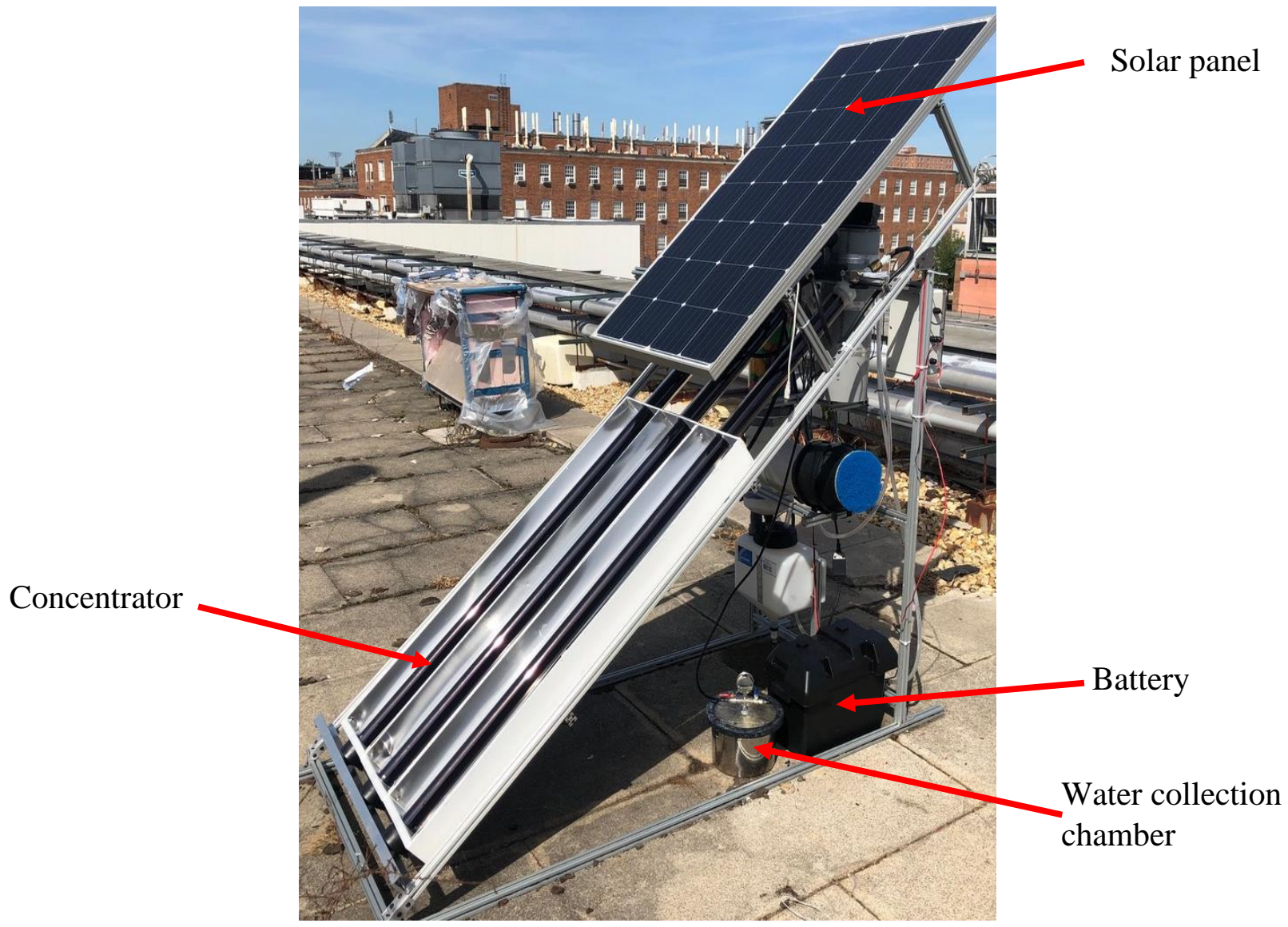

Figure 20 Corner view of the prototype 


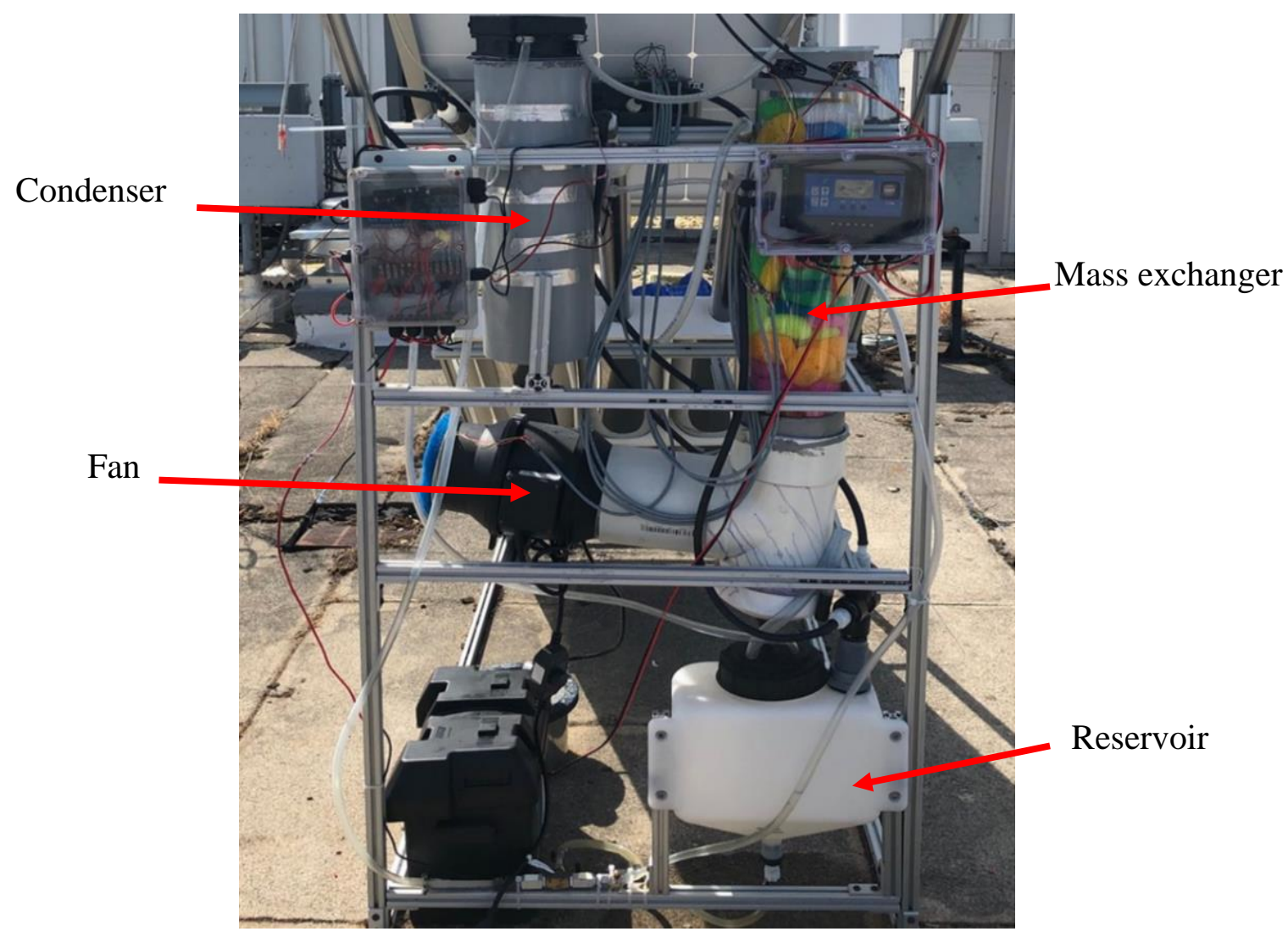

Figure 21 Backside view of the prototype

\subsection{Measurements and uncertainties}

\subsubsection{Measuring Relative Humidity and Temperature}

AM2302 DHT sensors by ASAIR were used for measurement of relative humidity and temperature at the inlet and outlet of mass exchanger during night operation. A total of four of these sensors were used. One humidity sensor is placed at the inlet of the mass exchanger and three sensors were placed at the exit of the mass exchanger. The sensors were calibrated before use with a calibrated hygrometer in the lab. The accuracy of the measurement details provided by the manufacturer are: 
Table 4 Technical details of the humidity sensor

\begin{tabular}{lc}
\hline Parameter & Value \\
\hline Humidity range $(\%)$ & $0-99.9$ \\
Temperature range $\left({ }^{\circ} \mathrm{C}\right)$ & $-40-80$ \\
Humidity precision $(\%)$ & 2 \\
Temperature precision $\left({ }^{\circ} \mathrm{C}\right)$ & 0.5 \\
\hline
\end{tabular}

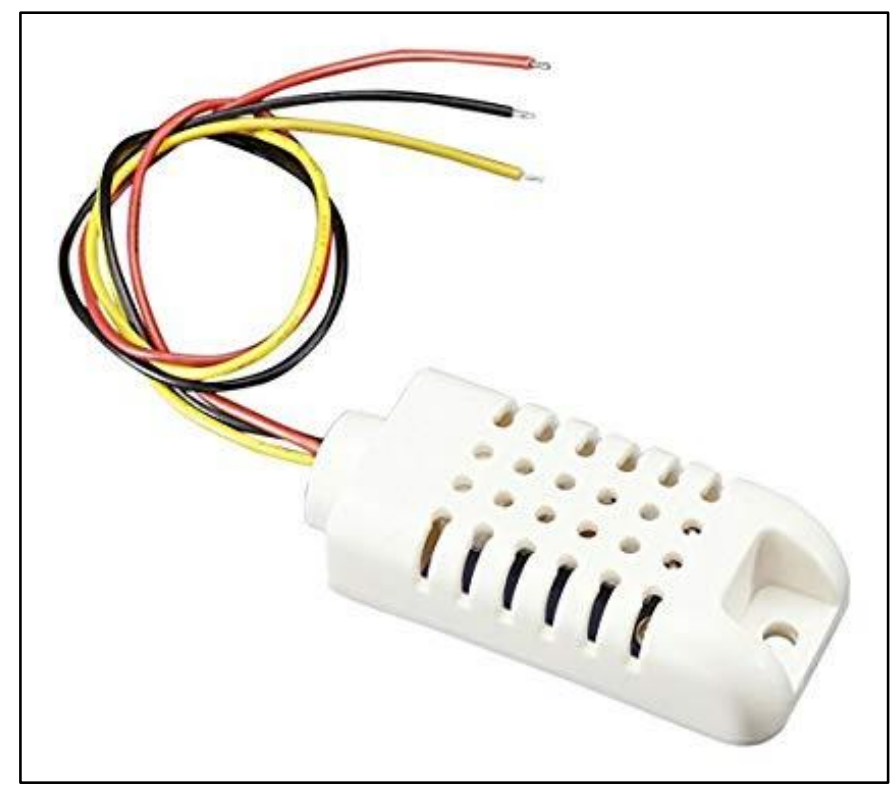

Figure 22 AM2302 DHT Sensor

\subsubsection{Measuring density and temperature of liquid desiccant}

Promass $83 \mathrm{M}$ digital Coriolis mass flow meter has been used for measurement of the density of the desiccant and temperature at the inlet of the mass exchanger, which are utilized in calculating the effectiveness of the mass exchanger. 
Table 5 Technical parameters of a mass flow meter as given by the manufacturer

\begin{tabular}{lc}
\hline \multicolumn{1}{c}{ Parameter } & Value \\
\hline Density range $(\mathrm{g} / \mathrm{cc})$ & $0-5$ \\
Precision in density measurement $(\mathrm{g} / \mathrm{cc})$ & 0.01 \\
Temperature range $\left({ }^{\circ} \mathrm{C}\right)$ & $-50-200$ \\
Temperature precision $\left({ }^{\circ} \mathrm{C}\right)$ & $0.5+0.05 * \mathrm{~T}$ \\
\hline
\end{tabular}

\subsubsection{Measuring total solar energy}

A light meter has been used to estimate the total solar irradiation incident on the concentrator for a day. The hourly light intensity in kLux was matched with the peak hourly solar beam radiation in $\mathrm{W} / \mathrm{m}^{2}$ observed during solar noon calculated using formula taken from ASHRAE's clear sky model [49] to calculate the multiplication factor in $\mathrm{W} / \mathrm{m}^{2} / \mathrm{kLux}$. Total normal radiation is given by equation 22 .

$$
I_{D N}=A e^{-\left(\frac{B}{\cos \theta_{z}}\right)}
$$

Here, A and B are constants given by ASHRAE's model for every month in and $\theta_{z}$ is zenith angle calculated by equation $24 . I_{D N}$ is direct normal radiation on an earth's surface. The total beam radiation incident on the inclined surface is given by equation 23 .

$$
I_{N}=I_{D N} * \cos \theta_{0}
$$

Where $\theta_{0}$ is the angle of incidence calculated by equation 25 and $I_{N}$ is the beam radiation incident on a surface.

$$
\cos \theta_{z}=\sin \delta \sin \varphi+\cos \delta \cos \varphi \cos \omega
$$




$$
\cos \theta_{0}=\sin \delta \sin (\varphi-\beta)+\cos \delta \cos (\varphi-\beta) \cos \omega
$$

Where is $\delta$ declination angle, $\varphi$ is the latitude of the location, $\beta$ is the angle of tilt of the surface facing equator and $\omega$ is hour angle.

The luminous intensity values were recorded every 5 seconds and an average value was calculated every 15 minutes. The average values obtained in kLux were converted into $\mathrm{W} / \mathrm{m}^{2}$ using the multiplication factor mentioned above. The sum of all the values in $\mathrm{W} / \mathrm{m}^{2}$ is taken as the total solar energy incident on the concentrator in $\mathrm{J} / \mathrm{m}^{2}$.

Table 6 Technical parameters of digital light meter as given by the manufacturer

\begin{tabular}{cc}
\hline Parameter & Value \\
\hline Range (Lux) & $0-400,000$ \\
Precision (\%) & 10 \\
Resolution (Lux) & 0.01 \\
\hline
\end{tabular}

4.3.4 Measuring the total moisture absorbed

During the moisture absorption, the liquid desiccant is cycled throughout the solution circuit using a pump from the reservoir. Since a rectangular shaped plastic tank constant cross-section along the length was used as a reservoir, an inch scale ruler was attached to the reservoir to measure the level of the salt solution in the reservoir. The difference in the levels of the solution between the start of the absorption and end of the absorption process gives the value of the total moisture absorbed. Using the geometrical calculation, it is found out that a one-inch increase in level equaled 1.27 liter of volume increase. When the level in the reservoir reads 0 , the volume filled in the reservoir equals 2 liters. 


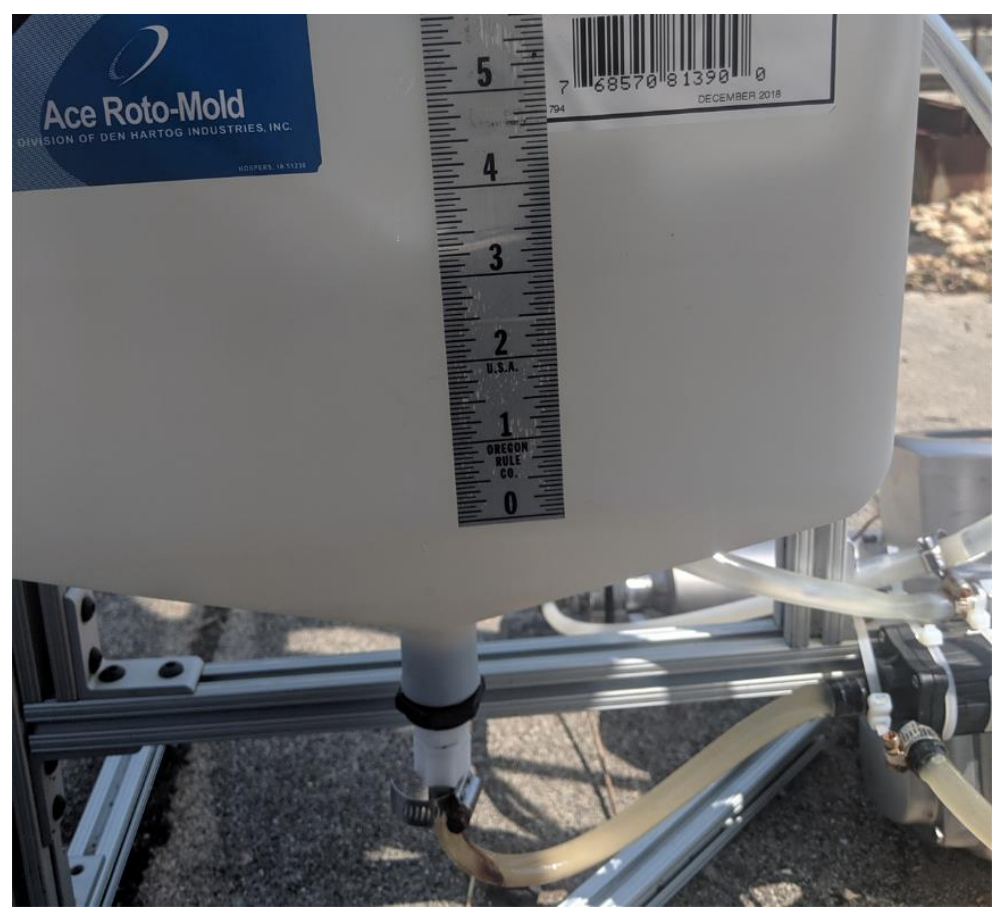

Figure 23 Reservoir with attached ruler 


\section{Results and discussion}

To estimate the performance of the proposed system, a prototype was designed and built as explained in chapters 3 and 4 and was installed on the roof of Glenn Martin Hall at the University of Maryland at College Park. Many trials were performed on the prototype and the weather conditions for the day of $1^{\text {st }}$ August 2019 were representative of actual field conditions, such as sunny and clear sky during the day and relative humidity $>70 \%$ in the night, ideal for a liquid desiccant system. Hence, $1^{\text {st }}$ August's data was chosen for further analysis.

\subsection{Solar concentration system results}

From NREL's data set for flat plate collectors and concentrators [50], for Maryland state for the month of July and August, a surface tilted at an angle equal to latitude $\left(\sim 39^{\circ}\right)$ receives $5.6 \mathrm{kWh} / \mathrm{m}^{2} /$ day and $5.5 \mathrm{kWh} / \mathrm{m}^{2} /$ day, respectively. Hence, for $1^{\text {st }}$ August an average of those values, $5.55 \mathrm{kWh} / \mathrm{m}^{2} /$ day was considered. The trial was carried out for 8 hours from 9 am to $5 \mathrm{pm}$ and the results are summarized below in Table 6 .

Table 7 Results for trials performed on solar concentration system

\begin{tabular}{ll}
\hline \multicolumn{1}{c}{ Parameter } & Value \\
\hline Volume of solution at the start (liter) & 4.8 \\
Density of solution at the start (g/cc) & 1.36 \\
Total time elapsed (hour) & 8 \\
Energy incident $(\mathrm{kWh})$ & 4.03 \\
\hline Water desorbed $(\mathrm{kg})$ & 1 \\
$\eta_{\text {sytem }}(\%)$ & 30 \\
\hline
\end{tabular}


The uncertainty in calculated energy obtained from datasheet is with an uncertainty of $\pm 9 \%$. Neglecting the uncertainty in the measurement of the total water desorbed, the uncertainty in calculation of efficiency is $\pm 9 \%$. To estimate the value of efficiency of the solar concentration system through measurements, an additional trial on solar concentration system was performed on the day of $10^{\text {th }}$ of October 2019 and a light meter was employed for measuring total incident solar energy using the procedure explained in section 4.2.3. The value of $I_{n}$ for solar noon was calculated as $849 \mathrm{~W} / \mathrm{m}^{2}$ and the value of Light intensity at solar noon was recorded as 105 Klux. Hence a multiplication factor of $8.2 \mathrm{~W} / \mathrm{m}^{2} / \mathrm{klux}$ is utilized to estimate the radiation intensity in $\mathrm{W} / \mathrm{m}^{2}$. The total solar radiation incident on the surface obtained was $5.1 \mathrm{kWh} / \mathrm{m}^{2}$ which is well within the range of 3.6-5.5 kWh/m²/day calculated from NREL's data set for Maryland state. The prototype system produced 1.2 liters after the system was exposed to solar radiation from 9:40 am to 5:16 pm and table 7 summarizes the system performance.

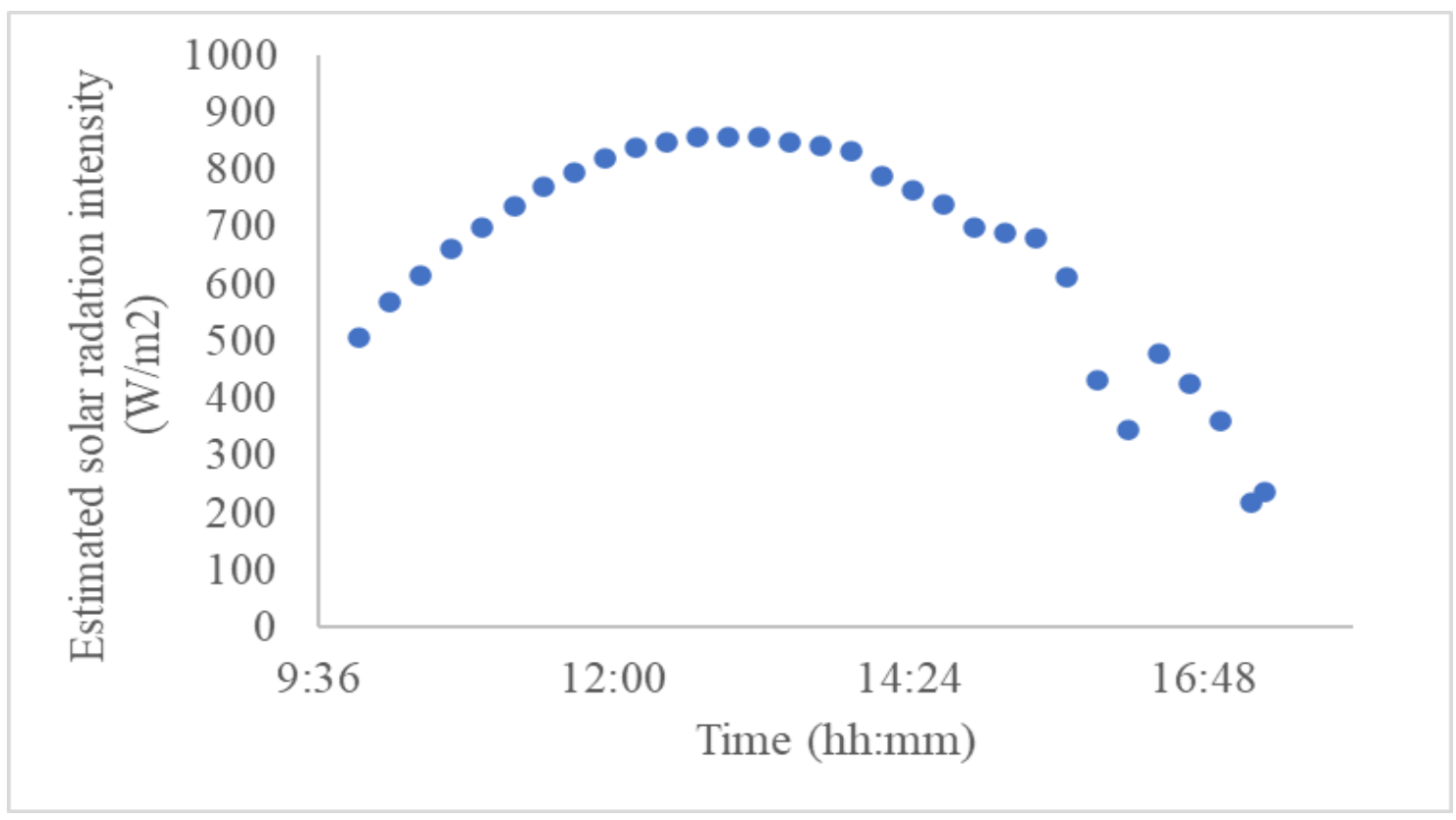

Figure 24 Estimated solar radiation variation with time for October 10th 
Table8 Results for solar concentration system trials performed on October 10th

\begin{tabular}{ll}
\hline Parameter & Value \\
\hline Volume of solution at the start (liter) & 5 \\
Density of solution at the start $(\mathrm{g} / \mathrm{cc})$ & 1.35 \\
Total time elapsed (hour) & 8 \\
Energy incident $(\mathrm{kWh})$ & 5.1 \\
\hline Water desorbed $(\mathrm{kg})$ & 1.2 \\
$\eta_{\text {sytem }}(\%)$ & 29 \\
\hline
\end{tabular}

\subsection{Mass exchange results}

The parameters which define the performance of a mass exchange system as described in chapter 3 are dehumidification effectiveness, total moisture absorbed, total time elapsed and energy consumed. All of the performance parameters mentioned above either directly or indirectly are functions of inlet desiccant solution concentration, inlet desiccant solution temperature, inlet desiccant solution flow rate, process air flow rate, inlet air humidity and inlet air temperature for a fixed mass exchanger geometry parameters. Hence all of the above variables are recorded with the help of DHT sensors measuring humidity and temperature of the air at inlet and outlet of the mass exchanger and Coriolis mass flow meter measuring density and temperature of the potassium formate solution at the inlet of the mass exchanger

The variation of psychrometric properties of air, relative humidity and temperature at the inlet and outlet of the mass exchanger (absorber) over the period of trial for which desiccant solution circulates through mass exchanger ( $~ 8$ hours) can be observed from figure 25 given below. 


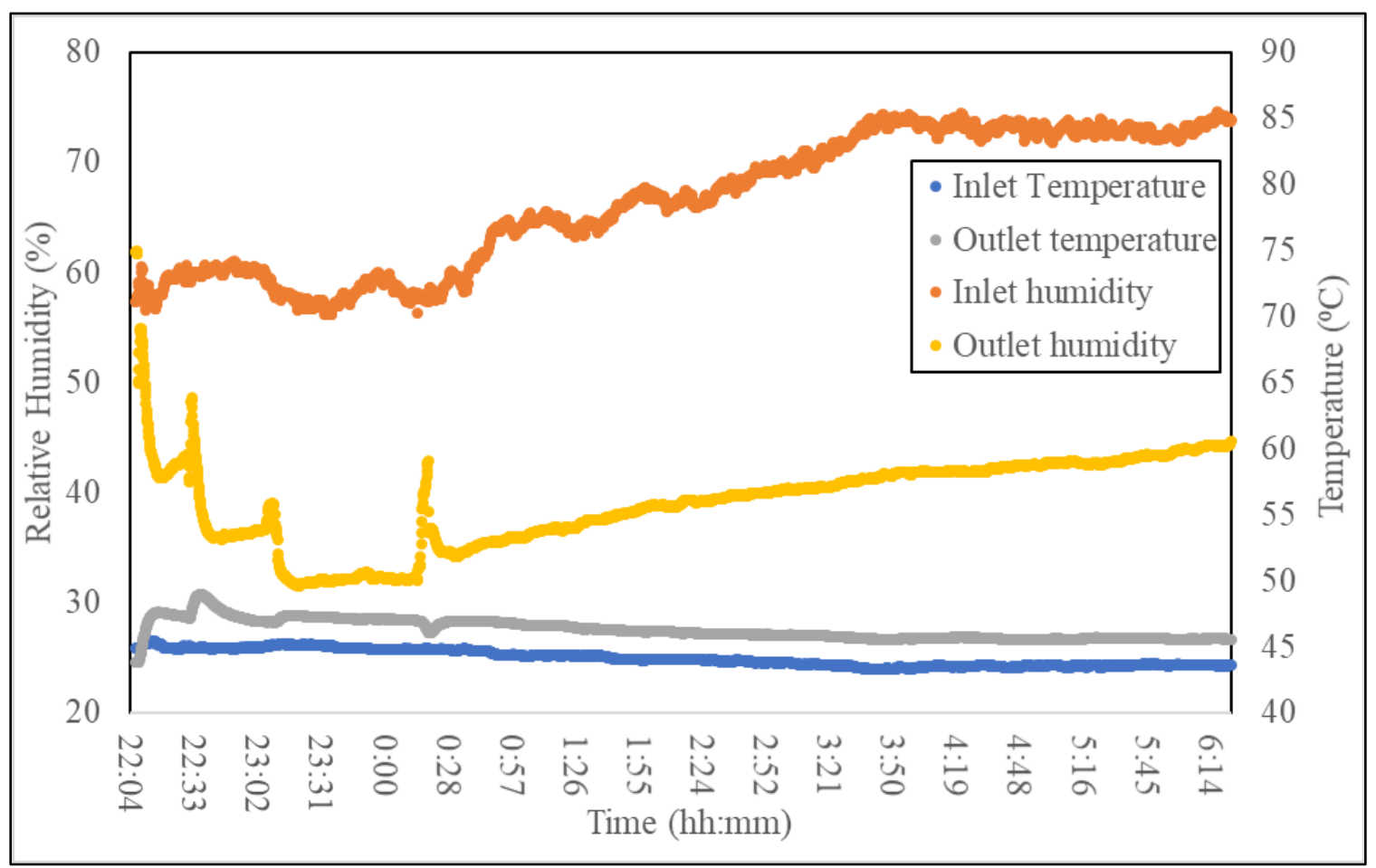

Figure 25 Trend of RH and temperature of process air at inlet and exit of dehumidifier

It can be observed from Figure 25 that $\mathrm{RH}$ at the inlet is greater than outlet $\mathrm{RH}$ suggesting the removal of moisture from the air. The temperature of the air at the outlet is greater than the inlet temperature due to the capture of heat of condensation by process air. Table 8 given below summarizes the result of the mass exchange process.

Table 9 Results of mass exchange process on $1^{\text {st }}$ August 2019

\begin{tabular}{ll}
\hline Parameter & Value \\
\hline Volume of solution at the start (liter) & 3.8 \\
Density of solution at the start (g/cc) & 1.48 \\
Density of solution at the end $(\mathrm{g} / \mathrm{cc})$ & 1.38 \\
Average temperature $\left({ }^{\circ} \mathrm{C}\right)$ & 25 \\
Average $\mathrm{RH}(\%)$ & 79 \\
dehumidification effectiveness $(\%)$ & 74 \\
Total time elapsed (hour) & 8 \\
\hline Water absorbed $(\mathrm{kg})$ & 1.3 \\
\hline
\end{tabular}


Based on the average values of temperature and relative humidity, $25^{\circ} \mathrm{C}$ and $79 \%$ respectively, the equilibrium density that can be attained is $1.22 \mathrm{~g} / \mathrm{cc}$. To achieve that density, the system should have had absorbed 4.2 liters of water from air. Hence the system absorbed only $28 \%$ of the maximum equilibrium water uptake. The uptake could be further increased by designing a mass exchanger bigger in size with a higher flow rate of desiccant solution, more packing material in the mass exchanger and higher airflow rate, etc.

\subsection{Discussion}

The designed prototype system has been tested at high relative humidity conditions ideal for liquid desiccant systems and the moisture that can be absorbed by mass exchanger during the night is equal to the moisture desorbed during the day. The remaining of this section discusses the performance comparison between the current system with other current water harvesting systems/methods.

The solar concentrating system has recorded a performance of $1.9 \mathrm{~kg} / \mathrm{m}^{2} / \mathrm{day}$, while from the literature review it can be observed that desiccant based systems have a performance ranging from $1.15-2.5 \mathrm{~kg} / \mathrm{m}^{2} /$ day. Hence the proposed system has a comparable performance in terms of moisture desorption capacity.

The potassium formate based prototype built for this project powered completely by solar energy as a standalone unit. If the system were to run on conventional energy sources, for example resistive heaters to boil the desiccant solution instead of solar concentration system, to produce 1.3 liters of water by boiling potassium formate solution, $1.7 \mathrm{kWh}$ of heat energy is required. $0.7 \mathrm{kWh}$ is required for the absorption of 1.3 liters of water from 
air at $25^{\circ} \mathrm{C}$ and $78 \% \mathrm{RH}$. Hence, the energy intensity rating calculated from the above values is $1.8 \mathrm{kWh} / \mathrm{liter}$.

From the investigation conducted on three different residential-size AWHs that utilize heat pumps for extraction of water from the air by Bagheri [6] in 2018, for warm and humid climates $\left(30^{\circ} \mathrm{C}\right.$ and $\left.62 \% \mathrm{RH}\right)$, the average energy requirement for AWHs was 1.02 $\mathrm{kWh} /$ liter. Hence, it can be stated that present-day AWHs based on heat pumps perform better than the current potassium formate based liquid desiccant system proposed at warm and humid conditions. However, heat pumps utilize refrigerants to generate a cold surface and refrigerants have significant global warming potential. On the other side, potassium formate is eco-friendly and non-toxic in nature. Considering the eco-friendly nature of the medium utilized, the proposed potassium formate based system has a significant advantage when compared with heat pump based AWHs.

From MOF- 801 's isotherms as seen in figure 7, it is evident that at $25^{\circ} \mathrm{C}$ and $80 \% \mathrm{RH}$, the maximum water uptake of MOF-801 was ranging from 0.3-0.4 $\mathrm{kg}$ of water $/ \mathrm{kg}$ of MOF. From $1^{\text {st }}$ August's mass exchange system's results, it can be stated that even with moisture absorption of only $28 \%$ of the equilibrium moisture uptake, the liquid desiccant absorbed $0.34 \pm 0.01 \mathrm{~kg}$ of water $/ \mathrm{kg}$ of desiccant solution. Hence it can be stated that liquid desiccants can have superior moisture uptake capacity at higher RH conditions when compared with MOF-801.

Wang [29] in 2018 developed a semi-open ACF-LiCl (sorbent bed) based device for extraction of water from air performed trials in which the absorption system was run for 40,000 seconds ( 11 hours) where the inlet air RH and temperature were constant at $85 \%$ 
and $30^{\circ} \mathrm{C}$ respectively for 6 hours. The sorbent bed weighing $40.8 \mathrm{~kg}$ absorbed $11.2 \mathrm{~kg}$ of water. The desorption process was carried out using solar air heaters and the system desorbed $9 \mathrm{~kg}$ of water. It can be calculated that the capacity of $\mathrm{ACF}-\mathrm{LiCl}$ is $0.2 \mathrm{~kg}$ of water per $\mathrm{kg}$ of sorbent while that of potassium formate liquid is around $0.34 \mathrm{~kg}$ of water per $\mathrm{kg}$ of the desiccant solution after running the absorber for 8 hours at $78 \% \mathrm{RH}$ and $25^{\circ} \mathrm{C}$. Hence it can be stated that the moisture uptake of the designed liquid desiccant systems is comparable to that of solid desiccant systems and can compete with current water extraction methods at high relative humidity conditions. 


\section{Conclusion and Future work}

\subsection{Conclusion}

Chapter 1 deals with the motivation for this project and the objective of this thesis. Chapter 2 provides details of the current AWVP technologies, advantages and disadvantages of each of the technology and their comparison with the liquid desiccant system. A liquid desiccant system with boiling as moisture desorption method and packed bed dehumidifier as absorber working on day and night respectively using an aqueous solution of potassium formate as the liquid desiccant has been proposed and the procedure followed for designing concentrating system and mass exchange system has been discussed in chapter 3 . The prototype setup, schematic and working of the absorption and desorption process has been explained in chapter 4 . A prototype was built, and trials were performed to record the performance metrics of the prototype. Details of the performance metrics of the prototype are provided in chapter 5 and explained in brief here.

For College Park, Maryland, in the month of August, a concentrator tilted at an angle equal to the latitude $\left(\sim 39^{\circ}\right)$ of the location receives $5.5 \mathrm{kWh} / \mathrm{m}^{2} /$ day of solar radiation as taken from NREL's data for the state of Maryland. The prototype system with $0.73 \mathrm{~m}^{2}$ surface area produced 1.4 liters of water through desorption on $1^{\text {st }}$ August, a clear and sunny day with a thermal efficiency of $30 \%$. To estimate the performance through a combination of solar radiation measurements and ASHRAE's clear sky model, an additional trial was performed on $10^{\text {th }}$ October, a clear and sunny day and the system produced 1.2 liters and system's efficiency obtained was $29 \%$. 
The mass exchange system trials were performed on $1^{\text {st }}$ August, the mass exchange trials were performed and after allowing the system to run for 8 hours, the system absorbed 1.3 liters of water. The total power consumed during the entire operation was $728 \mathrm{Wh}$. From section 5.3 it is evident that at higher relative humidity when comparing the moisture uptake values, potassium formate performs better than $\mathrm{ACF}-\mathrm{LiCl}$ and almost similar performance when compared with MOF-801. Currently, the AWHs based on heat pump requires less energy compared to the proposed liquid desiccant system for the extraction of water. But, the use of refrigerants which have a detrimental effect on the environment environments makes desiccant based systems eco-friendly and sustainable solution to extract water from the air. Hence it can be concluded that the proposed system is competitive when compared to current AWH systems/methods.

\subsection{Future work}

The performance of the proposed system is a function of many variables such as the available solar radiation for the concentrator, $\mathrm{RH}$ and temperature of ambient air at night etc. The variables mentioned above vary hugely over the period of a year for any location. Higher RH and temperature of air and high available solar radiation are favorable conditions for water extraction for liquid desiccant systems. Though the liquid desiccants have higher potential of moisture absorption at higher relative humidity levels $>70 \%$, they tend to lose moisture and ultimately crystallize at low RH conditions, typically $<30 \%$ for potassium formate, rendering the system inoperable and thereby limiting the range of $\mathrm{RH}$ in which the proposed system can operate. 
The trials performed on the prototype as mentioned in the results section does not provide a complete picture of the maximum and minimum extraction capacity of the proposed system. Hence much more data is needed to be collected in the future to capture the limitations and establish the performance metrics of the system over the working range of $\mathrm{RH}$, temperature and solar radiation values.

For a completely reliable and efficient system, irrespective of ambient conditions, water should be able to be extracted. MOFs and solid desiccants both have higher moisture uptake at low RH conditions and liquid desiccants have higher uptake at high RH conditions. In order to cover the entire range of the relative humidity, a hybrid system which contains solid desiccants/ MOFs, which are efficient at low relative humidity and liquid desiccants, which are efficient at higher relative humidity levels can be designed in future thereby making the hybrid system efficient for complete range of $\mathrm{RH}$ and temperature. 


\section{References}

[1] https://www.worldwildlife.org/threats/water-scarcity

[2] https://www.sciencedaily.com/terms/water_scarcity.htm

[3] https://www.unccd.int/sites/default/files/documents/12112014_Invisible\%20frontline

ENG.pdf

[4] Landsberg, H. E. (1972). Discussion, Beneficial Modifications of the Marine

Environment. Proceedings of Symposium Sponsored by National Research Council and

Dept. of the Interior, Washington, DC, March 11, 1968. Washington, DC: National

Academy of Sciences, $78-81$.

[5] Lowry W. (1972) Compendium of Lecture Notes in Climatology for Class IV Meteorological Personnel. World Meteorological Organization, Geneva, Reprinted in 1974.

[6] Bagheri, F. Performance Investigation of Atmospheric Water Harvesting Systems. Water Resour. Ind. 2018, 20 (Dec), 23-28.

[7] Afonso CFA. Recent advances in building air conditioning systems. Appl Therm Eng 2006;26:1961 -71

[8] Kim Hyunho, Yang Sungwoo, Furukawa, Umans Ari S, Rao Sameer R, Yaghi Omar M, et. al. Water harvesting from air with metal-organic frameworks powered by natural sunlight. Science 2017;356:430e4.

[9] Wahlgren RV. Atmospheric water vapour processor designs for potable water production: a review. Water Res 2001;35(1):1. 
[10] Schutte J.M., 1971: Die onttrekking van water uit die lae wolke op Mariepskop.

Technical note No. 20, Division of Hydrological Research, South African Department of Water Affairs, Pretoria.

[11] http://www.fogquest.org/

[12] Domen, J.K., Stringfellow, W.T., Camarillo, M.K. and Gulati, S. (2013). Fog water as an alternative and sustainable water resource. Clean Technol. Environ. Policy 16: 235249.

[13] Schemenauer, R.S. and Cereceda, P. (1991). Fog-water collection in arid coastal locations. Ambio 20: 303-308

[14] Schemenauer, R.S. and Cereceda, P. (1994a). Fog collection's role in water planning for developing countries. Nat. Resour. Forum 18: 91-100.

[15] Lummerich, A. and Tiedemann, K.J. (2011). Fog water harvesting on the verge of economic competitiveness. Erdkunde 65: 305-306.

[16] D.M. Fernandez, A. Torregrosa, P.S. Weiss Penzias, B.J. Zhang, D. Sorensen, R.E. Cohen, G.H. McKinley, J. Kleingartner, A. Oliphant, M. Bowman Fog water collection effectiveness: mesh intercomparisons Aerosol Air Qual. Res., 18 (2018), pp. $270-283$

[17] Qadir, Manzoor \& Jiménez, Gabriela \& Farnum, Rebecca \& Dodson, Leslie \& Smakhtin, Vladimir. (2018). Fog Water Collection: Challenges beyond Technology. Water. 10. 372. 10.3390/w10040372.

[18] https://www.climatetechwiki.org/content/fog-harvesting 
[19] https://en.wikipedia.org/wiki/Atmospheric_water_generator

[20] https://gr8water.net/

[21] skywater.com

[22] “AirDrop Irrigation Wins First Prize at 2011 James Dyson Awards"

https://bustler.net/news/2383/airdrop-irrigation-wins-first-prize-at-2011-james-dysonawards

[23] Dia Milani, et. al. Evaluation of using thermoelectric coolers in a dehumidification system to generate freshwater from ambient air Chem. Eng. Sci., 66 (2011), pp. 24912501

[24] Rahbar, Nader \& Esfahani, Javad. (2012). Experimental study of a novel portable solar still by utilizing the heatpipe and thermoelectric module. Desalination. 284. 55-61. 10.1016/j.desal.2011.08.036.

[25] S. Liu, W. He, D. Hu, S. Lv, D. Chen, X. Wu, et. al. Experimental analysis of a portable atmospheric water generator by thermoelectric cooling method Energy Proc, 142 (2017), pp. $1609-1614$

[26] S.L. James, 2003, Metal Organic Frameworks, Chem. Soc. Rev., 32,276

[27] H. Kim et. al., Science 10.1126/science.aam8743 (2017).

[28] Aristov YI, Glaznev IS, Freni A, Restuccia G. Kinetics of water sorption on SWS-1L (calcium chloride confined to mesoporous silica gel): influence of grain size and temperature. Chem Eng Sci 2006;61(5):1453e-8. 
[29] Wang, Jiayun \& Wang, R.Z. \& Wang, L.W. \& Liu, J.Y.. (2017). A high efficient semiopen system for fresh water production from atmosphere. Energy. 138. 10.1016/j.energy.2017.07.106.

[30] Aristov YI, Tokarev MM, Gordeeva LG, Snytnikov VN, Parmon VN. New composite sorbents for solar-driven technology of fresh water production from the atmosphere. Sol Energy 1999;66(2):165e8.

[31] Ji JG, Wang RZ, Li LX. New composite adsorbent for solar-driven freshwater production from the atmosphere. Desalination 2007;212(1e3):176e82.

[32] Kabeel AE. Water production from air using multi-shelves solar glass pyramid system. Renew Energy 2007;32(1):157e72.

[33] Wang, J., Liu, J., Wang, R. \& Wang, L. Experimental investigation on two solardriven sorption based devices to extract fresh water from atmosphere. Appl. Therm. Eng. 127, 1608-1616 (2017).

[34] H. I. Abualhamayel and P. Gandhidasan, A method of obtaining fresh water from the humid atmosphere, Desalination 113 (1997), 5 1-63.

[35] H. E. Gad, A. M. Hamed and I. EL-Sharkawy, Application of a solar desiccant/collector system for water recovery from atmospheric air, Renewable Energy 22 (2001), 451-556

[36] A. M. Hamed, Experimental investigation on the natural absorption on the surface of sandy layer impregnated with liquid desiccant, Renewable Energy 28 (2003), 1587-1596 
[37] P. Gandhidasan, H. Abualhamayel Investigation of humidity harvest as an alternative water source in the Kingdom of Saudi Arabia Water Environ., 24 (2010), pp. 282-292, 10.1111/j.1747-6593.2009.00189.

[38] G.E. William, M.H. Mohamed, M. Fatouh Desiccant system for water production from humid air using solar energy Energy, 90 (2015), pp. 1707-1720

[39] James, S. 1998. A new working Fluid 'Potassium Formate' for use in absorption heat pumps. Masters of Philosophy: The University of Nottingham.

[40] "Calcium chloride data sheet"

https://www.oxy.com/OurBusinesses/Chemicals/Products/Documents/CalciumChloride/1 73-01791.pdf

[41] ASHRAE (1993) Handbook of Fundamentals. American Society of Heating, AirConditioning and Refrigerating Engineers, Inc. (ASHRAE), Atlanta, GA.

[42] A. Rabl. Optical and thermal properties of compound parabolic collectors Solar Energy, 18 (1976), pp. 497-511

[43] Mohammed Moundji, Hadjiat \& Bekkouche, Sidi Mohammed El Amine \& Zerga, Abdellatif \& Benyoucef, Boumediene \& Yaïche, Redha. (2013). A New Modelling Approach of an ICS Solar Water Heater with CPC Reflectors. International Journal of Energy Engineering. 3. 165-170.

[44] Bhatia, S.C. Advanced Renewable Energy Systems; Woodhead Publishing: Delhi, India, 2014; pp. 1-31, 490-508.ISBN 978-1-78242-269-3

[45] Afonso CFA. Recent advances in building air conditioning systems. Appl Therm Eng 2006;26:1961 -71 
[46] "Crystallization temperature" https://formatebrines.com/manual/

[47] Sahlot, Minaal \& Riffat, Saffa. (2016). Desiccant cooling systems: A review. International Journal of Low-Carbon Technologies. 11. ctv032. 10.1093/ijlct/ctv032.

[48] Luo YM, Yang HX, Lu L, et al. A review of the mathematical models for predicting the heat and mass transfer process in the liquid desiccant dehumidifier. Renew Sustain Energy Rev 2014;31:587 -99.

[49] Liu XH, Jiang Y, Xia JJ, et al. Analytical solutions of coupled heat and mass transfer processes in liquid desiccant air dehumidifier/regenerator. Energy Conver Manag $2007 ; 48: 2221-32$.

[50] ASHRAE, Handbook of Fundamentals 1979, American Society of Heating, Refrigeration, and Air-Conditioning Engineers, New York; 1979

[51] Solar Radiation Data Manual for Flat-Plate and Concentrating Collectors https://rredc.nrel.gov/solar/pubs/redbook/PDFs/MD.PDF 